\title{
Jeomorfolojik Yaklaşıma Bağlı Heyelan Risk Değerlendirmesi: Kelkit Çayı Vadisi Aşağı Çı̆̆ırı Örneği*
}

\section{Landslide Risk Assessment Using a Geomorphological Approach: A Case Study of the Kelkit River Valley Downstream}

\author{
Mehmet Emin CİHANGİR ${ }^{1}$ (1)
}

${ }^{1}$ Dr. Öğr. Üyesi, Kahramanmaraş Sütçü İmam Üniversitesi, Fen Edebiyat Fakültesi Coğrafya Bölümü, Kahramanmaraş, Türkiye

ORCID: M.E.C. 0000-0001-8881-5308

\section{öz}

Kelkit Çayı Vadisinin aşağı çığııını oluşturan çalışma alanında keskin litolojik geçişler, yüksek topografik özellikler, klimatik ve tektonik özellikler bölgede dönemsel heyelanlanmaya neden olmaktadır. Çalışma kapsamında dönemsel aktiviteye bağlı gelişen heyelanların tehlike ve riskleri jeomorfolojik bir yaklaşımla değerlendirilmiştir. Bu bakımdan heyelan gelişimi Türkiye ortalamasının üzerindeki çalışma alanı için oluşabilecek kayıpların azaltılması amaçlanmıştır.

Çalışma alanında 462 heyelanın belirli topografik özelliklere ve litolojiye göre dağııım gösterdikleri belirlenmiştir. Heyelanların, vadi kuzeyinin üst kesimlerinde ve paleo-heyelan topoğrafyasında ani kar erimesiyle, güneyde ise yağışlarla tetiklendiği görülmüştür. Heyelan aktivitesi yüksek alanların, morfolojik evrimleri ve mekânsal sürekliliği 1958-2021 yılları arasında çok yüksek-yüksek çözünürlüklü uydu görüntülerinden (1 m ve 5 m) ve stereo hava fotolarından (1: 16,000-1:35,000 ölçekli) yorumlanmıştır. CBS ve UA araçlarıyla belirlenen çok zamanlı heyelan envanteri ile aktivitenin zamansal ve mekânsal farklılık gösterdiği görülmüştür. Aktivitenin yüksek ve risk elemanlarının olduğu dört bölgede tehlike, fiziksel, sosyal, sistemik ve ekonomik zarar görebilirliğe göre riskler değerlendirilmiştir. Heyelan tehlikesinin arttığı dönemlerde nüfus ve yerleşmenin yoğunlaştığı tespit edilmiştir. Koyulhisarın paleo heyelanlarının kuzeybatısında ve güneyindeki kısımlarda, Sugözü, Gökdere ve Boyalı heyelanlarının ise birikim zonuna yakın yerlerde risk elemanlarının ve dolayısıyla risk seviyesinin yüksek olduğu görülmüştür. Ayrıca Gökdere ve Boyalı heyelanlarının yeni bir aktivitede Kelkit Çayı́na set oluşturacağı tespit edilmiştir.

Anahtar kelimeler: Heyelan, Tehlike, Risk

\section{ABSTRACT}

Sharp lithological transitions, high topographic features, and climatic and tectonic features cause periodic landslides downstream of the Kelkit Creek Valley. Thus, the hazards and risks of landslides in the area were evaluated using a geomorphological approach to reduce the losses that may occur therein. It was determined that 462 landslides in the study area were distributed according to certain topographic features and lithologies. The landslides were triggered by rapid snow melting in the upper parts of the valley in the north and by paleo-landslide topography and precipitation in the south. The morphological evolution and spatial persistence of areas with high landslide activity were interpreted from very-high-resolution to high-resolution satellite images (1and $5 \mathrm{~m}$ ) and stereo aerial photos (1:16,000-1:35,000 scale) between 1958 and 2021. The landslide activities showed temporal and spatial differences with multitemporary landslide inventories determined using geographic information system and uncertainty analysis tools. Risks were evaluated according to the physical, social, systemic, and economic vulnerabilities in four regions with high activity and elements of risk. It was determined that the population and settlement densified during periods when landslide hazards increased. The risk elements and therefore the risk levels were high in the northwestern and southern parts of Koyulhisar and in the accumulation zone of the Sugozu, Gokdere, and Boyalı landslides.

Keywords: Hazard, Danger, Risk

*Bu çalışma, "Kelkit Çayı Vadisinde (Umurca-Koyulhisar Arası) Heyelan Riskinin Belirlenmesi” adlı doktora tez çalışmasından üretilmiştir.

Başvuru/Submitted: 18.07.2021 • Revizyon Talebi/Revision Requested: 27.12.2021 • Son Revizyon/Last Revision Received: 14.01 .2022 • Kabul/Accepted: 14.01.2022 - Published Online/Online Yayın: 17.02.2022

Sorumlu yazar/Corresponding author: Mehmet Emin CiHANGIR / m.e.cihangir@gmail.com

Atıf/Citation: Cihangir, M. E. (2022). Jeomorfolojik yaklaşıma bağlı heyelan risk değerlendirmesi: Kelkit Çayı Vadisi aşağı çığırı örneği. Cografya Dergisi. Advanced online publication. https://doi.org/10.26650/JGEOG2022-971673 


\section{EXTENDED ABSTRACT}

The study area, which is located in the downstream section (between the Umurca and Koyulhisar settlements) of the tectonically controlled Kelkit Creek Valley, has sharp lithological transitions and high topographic relief and hillslope gradient characteristics. These high topographic relief, slope, and lithological units and the climatic and tectonic features of the area have rendered it susceptible to landslides.

In this study, the occurrences of the landslides, their controlling factors, and the triggering mechanisms are discussed. Furthermore, the landslide risks were evaluated using a geomorphological approach to reduce the life and economic losses due to future landslide risks in the Kelkit Valley, which are above average in terms of landslide occurrence in Turkey.

A total of 462 landslides with areal extents ranging from 0.004 to $23.2 \mathrm{~km}^{2}$ were mapped, and their distribution characteristics were determined using geological and geomorphological conditions. The distribution of the landslides was not random in terms of geomorphology. That is, the landslides were distributed depending on certain slopes, reliefs, elevations, and lithologies. In terms of triggering factors, the landslides were triggered by the rapid melting of accumulated snow in the northern slopes of the valley, upper parts of the slopes, near-flat slopes of the plateau, and paleo-landslide topographies. Meanwhile, the landslides were triggered by antecedent precipitation in the southern slope. The short-term development, morphological evolution, and spatial persistence of the areas where the landslide activities were high were determined through a multitemporal geomorphological landslide inventory established using GIS and remote sensing tools from very-high-resolution and high-resolution satellite images (1-5 m) and stereo aerial photos (1:16,000-1:35,000 scale) between 1958 and 2016. On this basis, it was found that the landslide activities differed temporally and spatially. The landslide hazard was obtained by evaluating the landslide frequency and landslide intensity together. The physical, systemic, social, and economic vulnerabilities were evaluated using a geomorphological approach based on expert opinion in four regions (Koyulhisar, Sugozu, Boyali, and Gokdere) with risk elements out of five regions with high activities. The physical vulnerability of the structures and infrastructures of the study area was evaluated. In addition, the vulnerability of social elements (i.e., social vulnerability) and the economic vulnerability of the elements that individuals use to provide for their living expenses (e.g., agriculture field) were evaluated. The systemic vulnerability was evaluated as the loss of function of critical elements due to failures caused by physical damages. Moreover, according to the physical and economic vulnerabilities that a landslide may cause, risk losses and costs were calculated over current values.

The Sugozu and Koyulhisar Aklan regions emerged as the most dangerous areas in terms of landslide hazards. According to the level of hazard due to structural damages in Koyulhisar, the residence limit was determined as "H 24 (hazard: frequency $=2$, intensity $=4$ )." During periods of landslide activities, the landslide hazard increased, whereas the population and settlements densified and the landslide areas were opened to agriculture. According to physical vulnerability, the risk levels were high in areas near the slides and rockfalls northwest and south of the Koyulhisar paleo-landslide and the accumulation zones of the Sugozu, Gokdere, and Boyali landslides. The risk according to systemic and social vulnerabilities was determined southwest of Koyulhisar. According to economic vulnerability, the risk was determined at Koyulhisar and Gokdere. Furthermore, if the Gokdere and Boyali landslides were reactivated again, their landslide materials may block the Kelkit stream. 


\section{GİRIŞ}

Belirli bir zamanda ve belirli bir büyüklükteki tehlike karşısında maruz kalan insan ve insanın üretimlerinin (yapı, alt yapı, diğer ekonomik değeri olan varlıklar) fiziksel, sosyal, ekonomik ve sistemik zarar görebilirlik açıdan alabileceği kayiplara risk denir (Cruden \& Varnes, 1996; Cruden \& Fell, 1997; Dai \& Lee, 2002; Van Westen, 2017; Van Westen vd., 2006). Günümüzde nitel ve nicel yaklaşımlarla değerlendirilen (Dai vd., 2002; Guzzetti, 2006; Van Westen, 2017) heyelan risk değerlendirmeleri günümüzdeki şekline belirli aşamalarla gelmiştir. Bunların temelleri 1900'lerde Howe (1909) tarafindan heyelan aktivite periyodları ve süreç gelişiminin bölgesel değerlendirilmesine dayanmaktadır. 1950 sonrası dönemde Varnes (1958) tarafindan yapılan heyelan sinıflaması ve Jones (1961) tarafindan ise heyelan envanteri haritalama ve bölgesel tehlike değerlendirmeleri uygulaması ortaya konulmuştur. 1970'li yıllar Brabb ve Pampeya (1972)'nın bölgesel heyelan duyarlılık haritası ve Varnes'in (1978) heyelan sinıflama iyileştirmesiyle devam etmiştir. 1980'lerde ise Cannon ve Ellen (1985) tetikleyici heyelanlar için bölgesel yağışların eşik değerlerini belirleme, Wieczorek (1984) 'un Tehlike değerlendirmesi ve azaltılması çalışmaları, Wieczorek vd. (1985)'nin depremin tetiklediği heyelan duyarlılık haritası gibi çalışmalar göze çarpmaktadır. 1990'lı yıllara gelindiğinde CBS teknikleri ile oluşturulan heyelan duyarlılık, tehlike analizleri ve sınıflamaları görülmektedir. Bunlara örnek vermek gerekirse Cruden and Varnes (1996)'ın heyelan siniflama sistemlerini geliştirmesi, Iverson vd. (1998)'nin moloz akması tehlike modeli, Cruden ve Fell (1997)'in heyelan risk değerlendirme çalışması ve Guzetti vd. (1999)'nin heyelan tehlike değerlendirmesi çalışmalarına rastlanmaktadır. 2000 yılından günümüze doğru duyarlılık ve tehlike çalışmaları yaygınlaşmıştır. $\mathrm{Bu}$ çalışmalar ilk başlarda tek bir yöntemin kullanılması ile yapılırken günümüze yaklaştıkça birden fazla yöntemin karşılaştırılması şeklinde ortaya konulmuştur. Van Westen vd., (2006) bu çalışmaları sistematik olarak 4 ana grup altında toplamıştır. Heyelan envanteri temelli olasılık yaklaşımı (Chau vd., 2004; Guzzetti vd., 2005), sezgisel yaklaşım (doğrudan; jeomorfolojik haritalama veya dolayli; parametre haritalarının çakıştırılarak kesişim alanların tespit edilmesi) (Ayenew \& Barbieri, 2005; Gökceoglu \& Aksoy, 1996; Pachauri vd., 1998; Pachauri \& Pant, 1992; Ruff \& Czurda, 2008; Wachal \& Hudak, 2000), istatistiksel yaklaşım (iki değişkenli veya çok değişkenli) (Atkinson \& Massari, 1998; Carrara vd., 1991; Dai vd., 2002; Guzzetti vd., 1999; Malamud vd., 2004; Nandi \& Shakoor, 2010), deterministik yaklaşım (Cotecchia vd., 2009; Gökceoglu \& Aksoy, 1996; Van Westen \& Terlien, 1996) olarak siralanmaktadır. $\mathrm{Bu}$ siralamaya ek olarak, son yıllarda söz konusu analizlerin bilgi temelli yapay zekâ yöntemleri ile gerçekleştirilmesine ilişkin çalışmalar da görülmektedir (Ercanoglu \& Gokceoglu, 2002, 2004; Juang vd., 1992; Kanungo vd., 2006; Yesilnacar \& Topal, 2005). Heyelan risk değerlendirmeleri nitel ve nicel yöntemler olarak değerlendirilebilmektedir.

Heyelan risk çalışmaları dünyada çok fazla uygulanmamakla birlikte ülkemizde de örneklerine çok az rastlanmaktadır. Özellikle heyelan bakımından Türkiye ortalaması üzerinde olan (AFAD, 2020) ve heyelanın afet boyutunda gerçekleştiği Kelkit Vadisi gibi bölgelerde risk değerlendirmeleri afet öncesi tedbirler için önem taşımaktadır. Bu tarz çalışmalar afeti önleme ve zarar azaltmak için önemlidir. Çalışma alanında heyelana ilişkin duyarlılık ve heyelan mekanizmasına ilişkin çalışmalar bulunmamaktadır (Cihangir \& Görüm, 2016; Demir, 2018; Demirel vd., 2016; Hastaoğlu vd., 2014) yapılmasına rağmen heyelan riski bakımından ele alınmış bir çalışma. Bu amaçla bu çalışmada Cardinali vd., (2002)'nin nitel yöntemle ele aldığı jeomorfolojik yaklaşım çalışması Kelkit Vadisi Aşağı çı̆̆ırına uygulanmıştır. Fakat Cardinali vd., (2002)'nin risk değerlendirmesinde değerlendirilmesinde insan ve insan faaliyetlerinin gerçekleştĭgi yapı, altyapı ve iş alanlarını oluşturan unsurların fiziksel anlamda zarar görebilirlikleri içermektedir (Glade vd., 2006; Kappes vd., 2012; Papathoma vd., 2011) Bu çalışma ise (Cardinali vd., 2002)'nin çalı̧̧masının eksik yönlerini tamamlamaktadır. Bunu risk elemanlarının sadece fiziksel açıdan değil fiziksel hasardan kaynaklanan sistemsel arızalara bağlı olarak kritik unsurların fonksiyon kaybına uğrayabileceği ve faaliyetlerini sistemsel olarak aksatmasının ölçen (Hellström, 2007; Menoni vd., 2012; Menoni vd., 2002; Pascale vd., 2010) sistemik zarar görebilirlik ile yapmıştır. Bunun yanı sıra çalışma bireylerin zihinsel, sosyolojik ve demografik yönden zarar görebilirliklerini ifade eden (Cannon vd., 2003; Dwyer vd., 2004; Pelling, 2003) sosyal zarar görebilirlilik ve birey ve bireylerin ekonomik yaşam giderlerini sağladıkları unsurların ve imkân kapasitelerinin zarar görebilirliğini ifade eden (Adrianto \& Matsuda, 2002; Alcántara-Ayala, 2002; Galli \& Guzzetti, 2007; Raddatz, 2009) ekonomik zarar görebilirlik açıdan da heyelan risk değerlendirmesi yapmıştır. Risk değerlendirmesinin fiziksel, sosyal, sistemik ve ekonomik zarar görebilirlik açısından ele alınması zararın etki boyutunu anlaşılması açısından önemlidir (Cutter vd., 2003; Douglas, 2007). Çalışma alanında risk değerlendirmesi, risk elemanları bu dört zarar görebilirliğe göre değerlendirilmiştir. Uzman görüşüne bağl1 olarak risk elemanları üzerinde yapılan hasar incelemelerine bağlı tehlike seviyesine bağlı ikamet edilebilme sınırı belirlenmiştir. Risk 
elemanlarının bulunduğu tehlike zonuna ve zarar görebilirliklerinin durumuna göre risk seviyeleri ortaya konulmuştur. Ayrıca çalışma spesifik risk değerlendirmesinde zarar görebilirliği farklı zamanlarda gündüz ve gece senaryolarında değerlendirerek çalışmayı farklı zamana bağlı risk açısından değerlendirmiştir.

\section{2. ÇALIŞMA ALANI}

Tokat İli Reşadiye ilçesine bağlı Umurca köyü, doğuda Sivas İli Koyulhisar ilçesi Yukarıkale köyü arasında yer alan çalışma

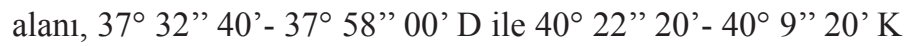
koordinatlarında bulunmaktadır. Alanın güney ve kuzey sınırları Yeşilırmak ana havzasının sınırlarını oluşturmaktadır (Şekil 1). Çalışma alanında Koyulhisar ilçesinin kuzeybatı kesiminde Aklan Çayında 19 Ağustos 1998 tarihinde yaklaşık hacmi $400.000 \mathrm{~m}^{3}$ boyutunda gerçekleşen heyelan $15 \mathrm{~km}^{2}$ 'lik bir alanı kaplamıştır (Yilmaz, 2009). Bu heyelan 21 Haziran 2000 de sabah saatlerinde yeniden hareketlenme ile birkaç evin yıkılmasına sebep olmuştur (Yilmaz, 2009). 2005 yılı Nisan ayında çalışma alanının batı kesiminde Kuzulu Mahallesi kuzeydoğusunda eski bir heyelan bölgesi üzerinde Sugözü heyelanı meydana gelmiştir (Gürsoy vd., 2006). Sorkun yaylasının 1500 ile 1650 m kotları arasında güneye doğru boşalan doğal su kaynaklarının bulunduğu alanda oluşan heyelan 15 kişinin hayatına, 21 evin yıkılmasına ve 375 hayvanın telef olmasına neden olmuştur (MTA, 2005).

Çalışma alanı tektonik birlik olarak Pontid kuşağı-Doğu Pontidlerin kuzey zonunda yer almaktadır (Okay, 2008). Bu alan Pontid-Anatolid kuşağını ayıran KAF (Kuzey Anadolu Fay)’ın Koyulhisar segmentini ve buna paralel fayları içermektedir (Duman vd., 2006; Toprak, 1989). KAF, Kelkit Çayı Vadisini kuzey ve güney olarak iki bloğa ayırmaktadır (Seymen, 1975). Çalışma alanındaki birimlere genel olarak bakıldığında; değişik fasiyeste kireçtaş1, volkanik/volkano-tortul ve kırıntılı tortul kayaçların yaygın olarak yüzeylendiği görülmektedir. Gevşek dokulu bu kaya birimleri yoğun biçimde ezilmiş, parçalanmış ve altere olmuştur (Gürsoy vd., 2006; Tatar vd., 2005). Volkanit kaya birimleri her iki blokta da yüzeylenmektedir. KAF'ın bulunduğu vadi yan yamaçlarında birimler genel olarak yüksek düzeyde deformasyona uğramışlardır (Tatar vd., 2012). Çalışma alanında KAF'ın kuzeyini oluşturan kuzey blok, Üst Kretase kireçtaşı, Pliyosen bazaltları, Eosen ve Üst Kretase volkanit çökel kayaları gibi litolojik birimlerle temsil edilmektedir (Erdem, 1987; Keçer, 1986; Yilmaz vd., 1985). KAF’ın batısında

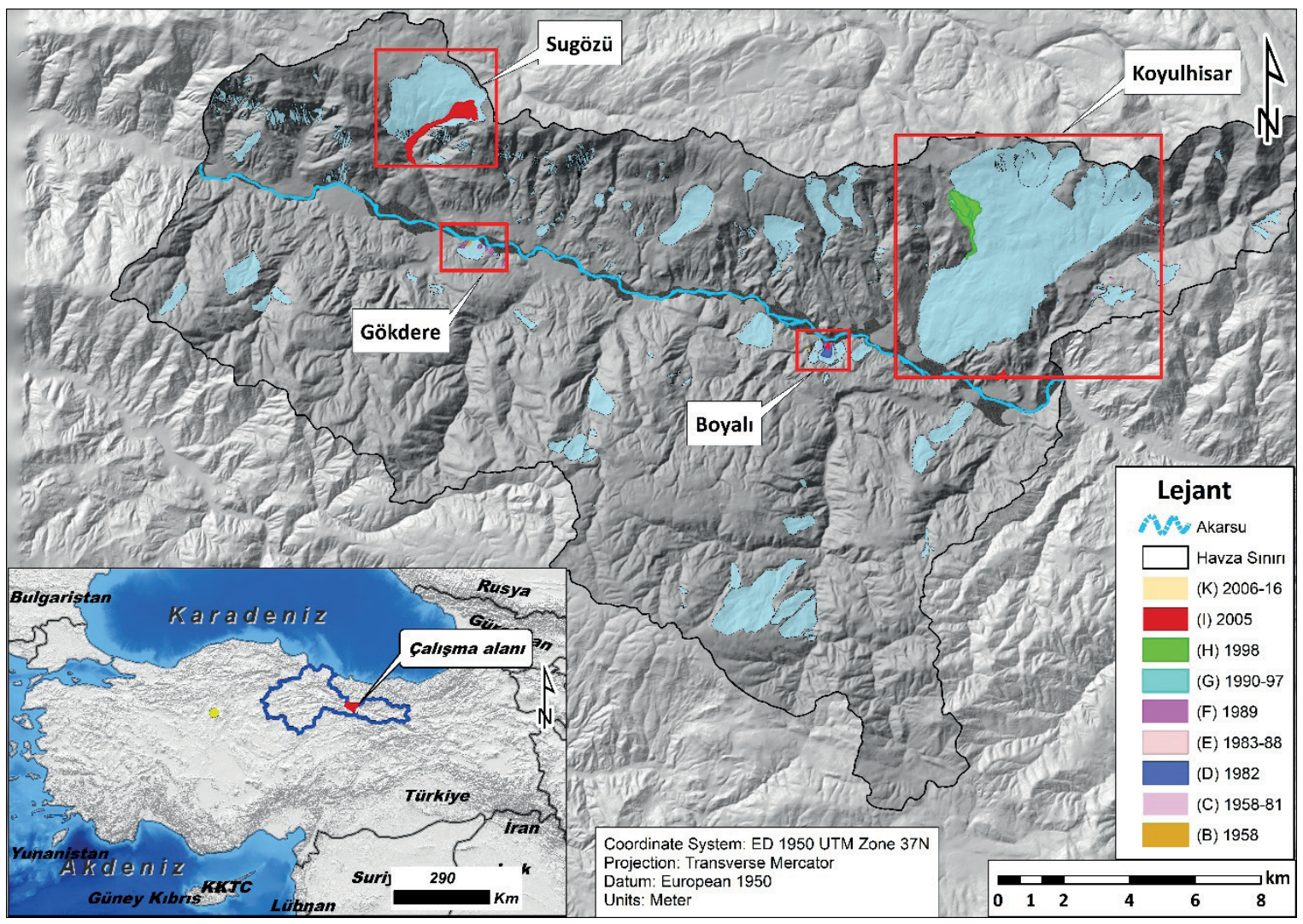

Şekil 1: Çalışma alanına ait lokasyon ve çok zamanlı heyelan envanteri haritası.

Figure 1: Location and multi-temporary landslide inventory map of the study area. 
ve doğusunda, fay zonuna yakın bölümde volkano-sedimenter kayalar ve Kuvaterner alüvyonları mevcuttur. Alanı, jeomorfolojik bakımdan; daha çok neotektoniğin denetiminde gelişmiş̧ir. Bu tektonik denetim sonucu, Kelkit Çayının derine kazmasının yüksek olduğu derin bir vadi sistemi oluşmuştur. Ayrıca bu tektonik denetim vadinin kuzeyi ile güneyi arasında bir asimetriye neden olmuştur (Cihangir \& Gorum, 2016). Bu asimetri sonucu olarak vadinin güneyi kuzeyinden daha eğimlidir. Ayrıca Gevşek ayrışmaya müsait litolojinin bulunması Kelkit Çayı ve kollarının yan ve derine aşındırmasının yüksek olmasına neden olmuştur (Gokceoglu vd., 2005; Yıldırım, 2006). Bu aşındırma süreci sonucu vadi yamaçlarında keskin röliyef farkı ve yüksek eğim oluşmaktadır. Ortalama eğimin $18,6^{\circ}$ olduğu çalışma alanında, eğim $60^{\circ}$ 'ye kadar çıkmaktadır. Taban seviyesini oluşturan çizgisel ve dar kanal eksenine sahip Kelkit Vadisi yüksek eğimlerle temsil edilen ortalama eğimleri $24^{\circ}$ yan yamaçlara sahiptir. Çalışma alanının ortalama yükseltisi $1283 \mathrm{~m}$, minimum yükseltisi 561,4 m, maksimum ise 2446,4 m'dir. Kısaca fay hattının uzandığı doğu-batı doğrultu boyunca derin bir vadi, bunun kuzey ve güney bloğunda ise kısa mesafelerde aniden yükselen bir topoğrafya mevcuttur (MTA, 2005).

Çalışma alanının kuzey bloğunda, yüksek yamaçların gerisinde Maestrihtiyen kireçtaşlarının yüzeylendiği ve içerisinde değişik boyutlarda karstik çukurların bulunduğu yapısal bir düzlük bulunmaktadır. Güney blok ise; engebeli topoğrafya su bölüm hattını oluşturan keskin sırt ve tepelerle çevrilidir. Her iki blok, egemen olarak yamaç süreçlerine bağlı kütle hareketleri ve flüvyal süreçler tarafından şekillenmektedir (Cihangir vd., 2018).

1984-1994 Devlet Meteoroloji Genel Müdürlüğü 800 m yükseltideki Koyulhisar ve 1970-2017 yılları arasındaki 1050 m yükseltideki Suşehri istasyon verilerine göre değerlendirildiğinde yağış genel olarak yağmur tipinde düşmektedir. Yağmur tipinde düşen bu yağışlar en fazla ilkbaharın nisan, mayıs aylarında sonra sonbahar ve kış mevsiminin tüm aylarında gerçekleşmektedir (Cihangir, 2018). Bölgede y1llık ortalama yağış 405.6 mm'dir. Toplam yağış ortalaması en yüksek mayıs $(61.6 \mathrm{~mm})$, en düşük ise ağustos $(5.6 \mathrm{~mm})$ ayıdır. Elde edilen sonuca göre yıllık toplam yağışın en düşük $27 \mathrm{~mm}$ olduğu en yüksek ise $944 \mathrm{~mm}$ olduğu görülmüştür. Çalışma alanında kar yağışı özellikle kış aylarında etkilidir. Özellikle vadinin yüksek kesimlerinde etkili olan karın yağdığı gün sayısı en çok aralık (19 gün) ve şubat (19 gün) aylarıdır. Kış aylarında yağan kar bakının etkisiyle yüksek kesimlerde uzun süre yerde tutunmaktadır (Cihangir, 2018).

\section{AMAÇ VE YÖNTEM}

Çalışmada heyelanın afet boyutunda gerçekleştiği Kelkit Vadisi bir bölgede afet öncesi tedbirler alınması gereken bölgelerin belirlenmesi için risk değerlendirilmesi amaçlanmıştır. Risk çalışması için zamansal heyelan haritası ve buna bağlı tehlike zonlarını oluşturmak ve bu zonlar içerisindeki risk elemanlarının maruz kaldığı tehlikeye karşı zarar görebilirliklerini değerlendirmek nihai olarak bölgede heyelan risk değerlendirmesi yapmak çalışmanın ulaşmak istediği sonuçtur.

$\mathrm{Bu}$ amaçla materyal olarak Harita Genel Müdürlüğünden temin edilen belirli yıllara ait 1: 15.000-1: 35.000 ölçekli (1958, 1963, 1973, 1986, 1990) stereo hava fotoğrafları kullanılmıştır. Sayısal yükselti modeli Harita Genel Komutanlığı'nın 1/25 binlik 6 adet topoğrafya haritasından (H39-a4, H39-a3, H39-b4, H39-b3, H39-d2, H39-c1) elde edilmiştir. Toprak haritası 1/25.000 olarak T.C. Gıda, Tarım ve Hayvancılık Bakanlığı Tarım Reformu Genel Müdürlüğünden temin edilmiştir. Yüksek ve çok yüksek çözünürlüklü 2006 yılına ait Spot $(5 \mathrm{~m})$ uydu görüntüsü, 2013 WorldView (1m) uydu görüntüsü kullanılmıştır. Ayrıca Google Earth 2020 görüntülerinden yararlanılmıştır.

Çalışmanın ilk aşamasını literatür tarama, veri toplama, verilerin düzenlenmesi, eksik verilerin tamamlanması, çalışma sürecinin planlanmasını oluşturmaktadır. İkinci aşama çalışma alanının güncel heyelan envanterinin oluşturulması ve uydu görüntülerinden morfolojik örüntüye bağlı olarak uzman tarafından tespit edilmesi ve bunların arazi çalışmalarıyla yersel kontrollerinin sağlanmasını içermektedir. Üçüncü aşama heyelan aktivitesinin zamansal dağılımını oluşturmaktadır. Bu aşama 1958-2020 y1lları arasında ortalama 10 yıl periyodlarında heyelanın yamaçlarda tekrar durumu ortaya konulmasını içermektedir. Dördüncü aşamada heyelan frekansının yüksek olduğu bölgelerde heyelanların yoğunluğu (hacim ve heyelan tipi) ortaya konulmuştur. Böylelikle bu aşama heyelan tehlike değerlendirme matrisini ( $\mathrm{F}=\mathrm{f}$ (sıklık, yoğunluk)) içermektedir. Beşinci aşama zarar görebilirlik değerlendirmelerini içermektedir. $\mathrm{Bu}$ aşama ise risk elemanları olarak belirlenen (nüfus, yap1, altyapı, kritik yapı, tarım) unsurlara ait fiziksel, sistemik, sosyal ve ekonomik zarar görebilirlik değerlendirmelerini içermektedir. Altıncı aşama tehlike zonu içerisinde bulunan risk elemanın zarar görebilirliğini kapsayan kısacası tehlike ve zarar görebilirlik kesişimini içeren risk değerlendirmeleri oluşturmaktadır (Şekil 2). Çalışmada ayrıca risk durumlarına ilişkin maliyet hesaplamaları da yapılmışıtır. Bunun yapımında yol için karayolları yol yapım maliyeti, yapı ve tarla için ise emlak sitelerinden belirlenen güncel emlak 


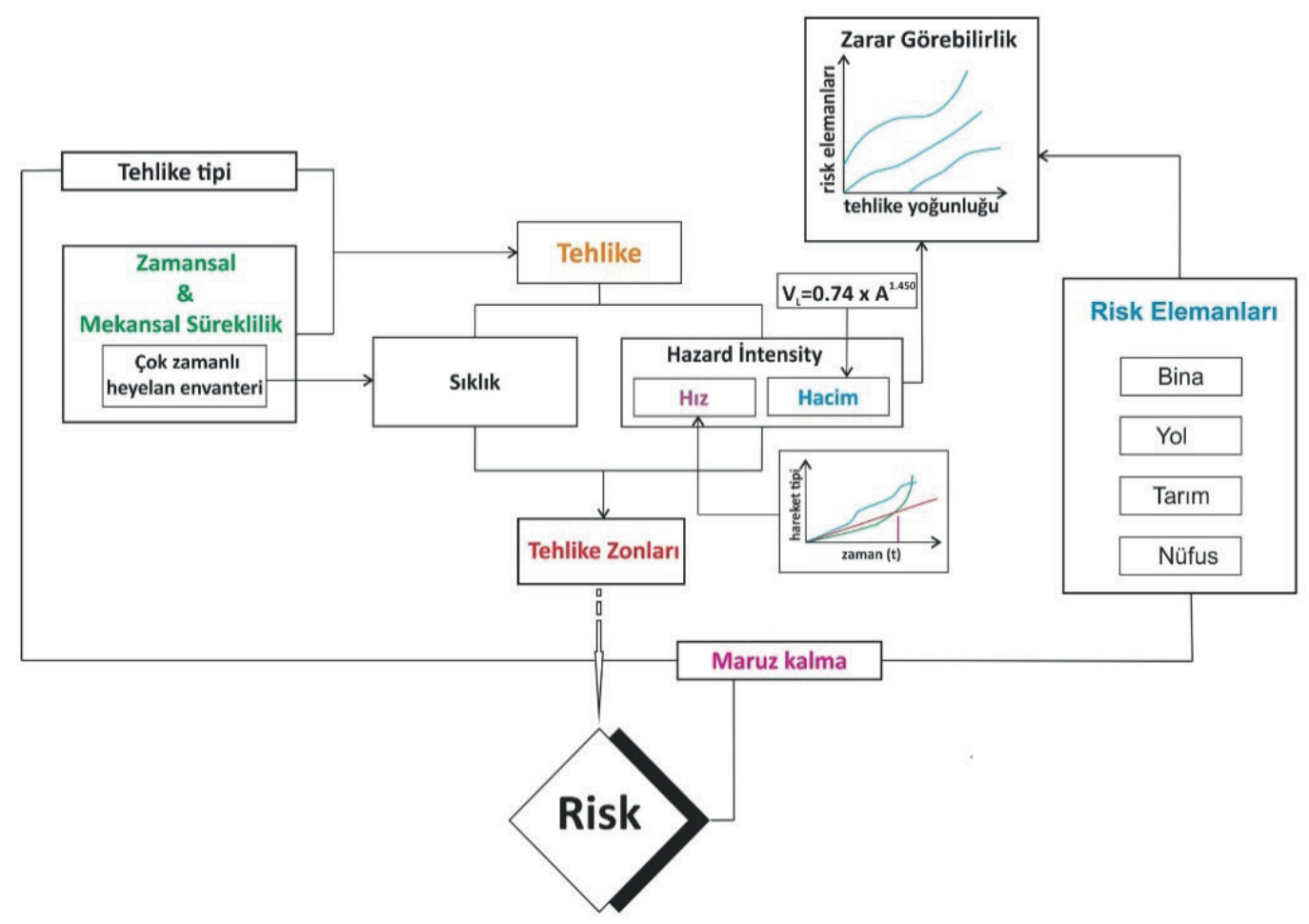

Şekil 2: Jeomorfolojik yaklaşıma dayalı risk değerlendirmesinin genel iş akış şeması.

Figure 2: General work flowchart of risk assessment based on geomorphological approach.

indeksi (arsa, tarla ve ev ait güncel ortalama $\mathrm{m}^{2}$ fiyat) kullanılarak hesaplanmıştır.

Çalışmada veri eksikliğinden kaynaklı birtakım engellerle karşılaşılmıştır. Bunların başında geçmiş dönemlere ait veri sınırlılığıdır. Geçmiş yıllara ait hava fotoğrafları için en eski dönem 1958 yılına aittir. Ayrıca hava fotoğrafı görüntülerinin ölçeklerinin birbirinden farklı olması, heyelan envanterinin en küçük hava fotoğrafı ölçeğine (1: 35.000) göre referans alınmasına neden olmuştur. Veri sınırlılığına rağmen çalışma sayesinde heyelan risk değerlendirmesi açısından bölgede afet öncesi tedbirler alınması için karar vericilere fikirler sunması açısından önemli sonuçlar elde edilmiştir.

\section{BULGULAR}

\subsection{Tehlike Değerlendirmesi}

Heyelan tehlikesi genel anlamda heyelanın dönüş periyodunu ve büyüklügünü dikkate alınarak, heyelan büyüklüğünün zamansal olabilirliğinin ifade edilmesidir (Cardinali vd., 2007; Cardinali vd., 2002; David Cruden \& David Varnes, 1996; Van Westen, 2017; Van Westen vd., 2006).
Heyelan frekansı ve heyelan yoğunluğu olmak üzere iki faktörün kesişimiyle heyelan tehlikesi elde edilmiştir (Tablo 3). Frekans ve yoğunluk faktörleri heyelan tehlikesinin temeli olan heyelanın büyüklüğü ve zamansal olabilirliğinin de ortaya konulmasını sağlamaktadır.

İlk etken olan heyelan frekansı belirli bir alanda heyelanın kaç defa tekrar ettiğini göstermektedir (Tablo 1). Aynı zamanda frekans zaman içerisinde olayın gerçekleşme olabilirliğini de ifade etmektedir. En basit zaman birimi olarak yıl bazında hesaplanabilmektedir. Örneğin bir bölgede, 100 yıllık kayıtta (t) 5 heyelan (n) gözlenirse, (n/t) heyelanın ortalama dönüşüm aralığg 20 yıl demektir. Bölge yıllık \%5' heyelan olabilirliğine sahip demektir (Crozier \& Glade, 2005).

Çalışma alanı için elde edilen envanter kayıtlarında ise; 1958-2020 (62 yıl) yılları arasında 67 heyelanın meydana geldiği tespit edilmiştir.

[70 (n) /62 (t y1l)] = Koyulhisar Vadisi aşağı kesiminde heyelanın yıllık olabilirliği \%113 demektir. Ortalama dönüşüm periyodu 0.88 (320 gün) yıldır. Kısacası çalışma alanında her 320 günde bir heyelan gerçekleşmektedir. $\mathrm{Bu}$ sonuca göre çalışma alanında tehlikenin zamansal olabilirliği çok yüksektir. 
Tablo 1: Frekansına göre heyelan değerlendirmesi (Cardinali vd., (2002)'den uyarlanmıştır).

Table 1: Evaluation of landslides by frequency (adapted from Cardinali et al., (2002)).

\begin{tabular}{ccccc}
\cline { 2 - 5 } & Düşük & Orta & Yüksek & Çok yüksek \\
\cline { 2 - 5 } Tekrar sayısı & 1 & 2 & 3 & $>=4$ \\
\hline \hline
\end{tabular}

Heyelan yoğunluğu, tehlike değerlendirmesinde ve risk elemanlarını fiziksel zarar görebilirlik değerlendirilmesinde kullanılmaktadır (Cardinali vd., 2002). Tehlike değerlendirmesinde frekanstan sonra ikinci etken olan heyelan yoğunluğu, hacim ve heyelan tipine bağlı tahmini hızın kesişiminden elde edilmektedir (Tablo 2). Hacim hesaplama,

Tablo 2: Heyelan yoğunluğu matrisi Cardinali vd. (2002)'den uyarlanmıştır).

Table 2: Landslide intensity matrix (adapted from Cardinali vd., (2002)).

\begin{tabular}{l|c|c|c} 
Hacim $\left(\mathbf{m}^{\mathbf{3}}\right)$ & $\begin{array}{c}\text { Çok Hızlı Heyelan } \\
\text { (Kaya Düşme) }\end{array}$ & $\begin{array}{c}\text { Hızlı Heyelan } \\
\text { (Moloz Akma) }\end{array}$ & $\begin{array}{c}\text { Yavaş Heyelan } \\
\text { (Kayma) }\end{array}$ \\
\hline$<0.001$ & Yavaş & & \\
$<0.5$ & Orta & \\
$>0.5$ & Yüksek & Yavaş \\
$<500$ & Yüksek & Yavaş & Orta \\
$500-10000$ & Yüksek & Yüksek & Öra \\
$10000-50000$ & Çok Yüksek & Çok Yüksek & Yüksek \\
$>500000$ & \multicolumn{3}{|c|}{ Çok Yüksek } \\
\hline$>500000$ & \multicolumn{3}{|c}{} \\
\hline
\end{tabular}

heyelanın mekanizmasından dolayı oldukça zordur. Çünkü hacim hesaplanmasında kullanılan derinlik bilgisi heyelanın farklı kısımlarına göre değişkenlik göstermektedir. Bunun yanı sıra büyük ana kaya heyelanlarında derinliğin çok yüksek olmasından dolayı hesaplama (sondaj) maliyeti de yüksektir. Bu sebeple hacim hesaplamasında heyelan alanından hacim dönüştürme yöntemi kullanılmıştır.

Heyelan hacimi aşağıdaki belirtilen şekilde formüle edilmektedir:

$\mathrm{V}_{\mathrm{L}}=0.74 \times \mathrm{A}^{1,450} \quad$ Eşitlik 1 (Guzzetti vd., 2009).

Burada $V_{L}$ heyelan hacmini, $A$ ise heyelan alanını ifade etmektedir.

Heyelan aktivitesinin yüksek olduğu beş bölgede (Koyulhisar, Sugözü, Boyalı ve Gökdere) heyelan yoğunluğunun da yüksek olduğu tespit edilmiştir. Bu beş bölgede orta, yüksek ve çok yüksek derecede yoğunluğa sahip heyelanlar bulunmaktadır. Boyalı ve Gökdere heyelanlarının farklı kesimlerinde orta, yüksek ve çok yüksek seviyede heyelan yoğunluğu gözlenmektedir (Şekil 3 (a ve b)). Koyulhisar paleo-heyelanı ve bu heyelanın farklı kesimlerinde gelişen heyelanların yoğunluğu çok yüksektir (Şekil 3 (c)). Gökdere'nin güneyindeki heyelanlar ise, yüksek ve çok yüksek yoğunluğa sahiptir (Şekil 3 (d)). Sugözü paleo-heyelan topoğrafyasındaki heyelanlara
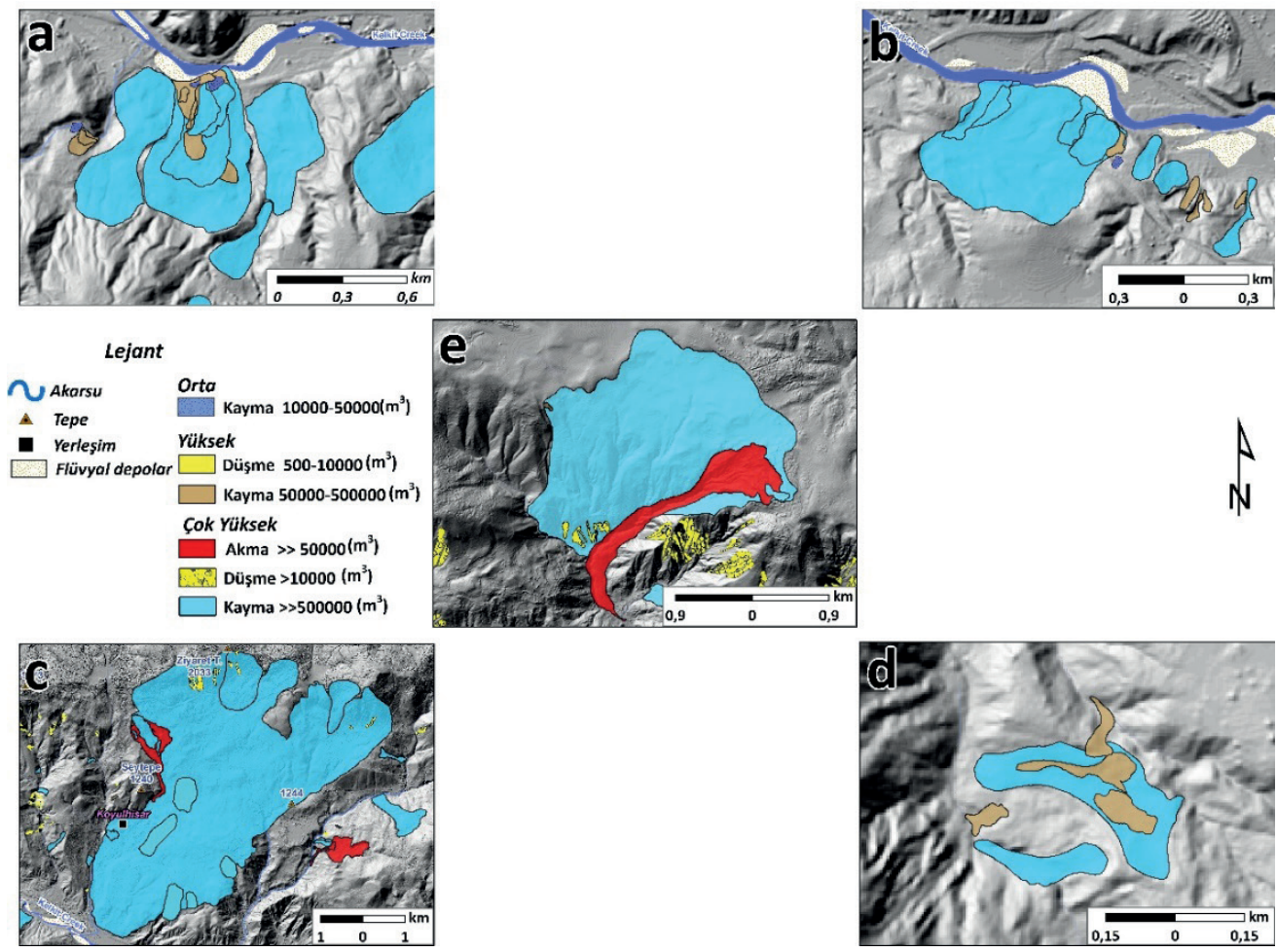

Şekil 3: Çalışma alanında heyelan aktivitesi yüksek beş bölgenin heyelan yoğunluğu dağılımı.

Figure 3: The landslide intensity distribution of the five regions with high landslide activity in the study area. 
baktığımızda, burada heyelanların çok yüksek yoğunluğa sahip olduğu görülmektedir.

Risk değerlendirmesinin bir önceki aşamasını ve temelini oluşturan Heyelan Tehlike Zonu (HTZ), aynı yamaçta heyelan frekansı ve yoğunluğunun kesişimine (HTZ= f (frekans, yoğunluk)) bağlı olarak elde edilmektedir (Tablo 3). Tehlike zonlarında tehlikenin şiddetinin artmasına en büyük etken heyelan frekansıdır. Heyelan frekansı artıkça heyelanın tehlikesi de artmaktadir.

Tablo 3: Heyelan tehlike değerlendirme matrisi ( $F=f$ (sıklık, yoğunluk)) matrisi Cardinali vd., (2002)'den uyarlanmıştır).

Table 3: Landslide hazard matrix (adapted from Cardinali et al., (2002)).

\begin{tabular}{l||cccc}
\cline { 2 - 5 } & \multicolumn{4}{c}{ Heyelan yoğunluğu } \\
\hline $\begin{array}{l}\text { Heyelan } \\
\text { frekansı }\end{array}$ & Düşük (1) & Orta (2) & Yüksek (3) & Çok yüksek (4) \\
\hline \hline Yavaş (1) & 11 & 12 & 13 & 14 \\
\hline Orta (2) & 21 & 22 & 23 & 24 \\
Yüksek (3) & 31 & 32 & 33 & 34 \\
\hline Çok yüksek (4) & $>=41$ & $>=42$ & $>=43$ & $>=44$ \\
\hline \hline
\end{tabular}

Çalışma alanının tehlike zonlarının belirlenmesinde, zamansal heyelan aktivitesi ve heyelan yoğunluğunun yüksek olduğu beş bölge üzerine odaklanılmıştır. Heyelan tehlike zonlamasında kullanılan ifadeler tehlike seviyesini ifade etmektedir. Örneğin “T 34” ifadesinde "T tehlike" "3 frekans sayısını", "4 ise yoğunluğu (Çok yüksek)" ifade etmektedir.

Heyelan tehlike seviyesi, beş bölgede en düşük " $\mathrm{T}$ 12" ve en yüksek ise "T 44" arasında olmak üzere farklı seviyelerde görülmektedir. Çalışma alanında beş bölgeye incelendiğinde; Boyalı heyelanının transfer ve birikim kısmında farklı seviyelerde heyelan tekrarlanmaktadır. $\mathrm{Bu}$ heyelanın transfer kısmı orta seviyelerde tehlike "T 23 ve "T 24" oluştururken, birikim kısmı ise çok yüksek "T 43" ve "T 44" gibi tehlike zonlarını oluşturmaktadır (Şekil 4 (f)). Gökdere heyelanın birikim kısmında ise çok yüksek seviyede "T 34 ve "T 44" tehlike zonları bulunmaktadır (Şekil 4 (g)). Çok yüksek heyelan yoğunluğuna sahip Koyulhisar paleo-heyelan alanına baktığımızda bu heyelanın farklı kesimlerinde yenilenen heyelanlar farklı tehlike seviyeleri içermektedir. Bu heyelanın kuzeybatısındaki Aklan heyelanın tehlikesi "T 44" seviyesinde çok yüksek boyuttadır. Bunun dışında Koyulhisar paleo-heyelanın güneyinde Koyulhisar ilçe merkezinin bulunduğu kısımda heyelan seviyesinin "T 24" orta düzeyde olduğu görülmektedir. Ayrıca bu paleo-heyelanın ana ayna kesiminde orta düzeyde "T 23" tehlikeli kaya düşmeleri de görülmektedir. $\mathrm{Bu}$ paleo-heyelanın ikinci bir heyelanın yenilenmediği diğer kısımları ise düşük tehlike seviyesindedir (Şekil 4 (h)). Gökderenin güneyinde ise, düşük "T 14”, orta "T 23", yüksek "T 33" ve çok yüksek "T 43" seviyelerinde tehlike zonları olduğu tespit edilmiştir (Şekil 4 (1)). Sugözü paleo-

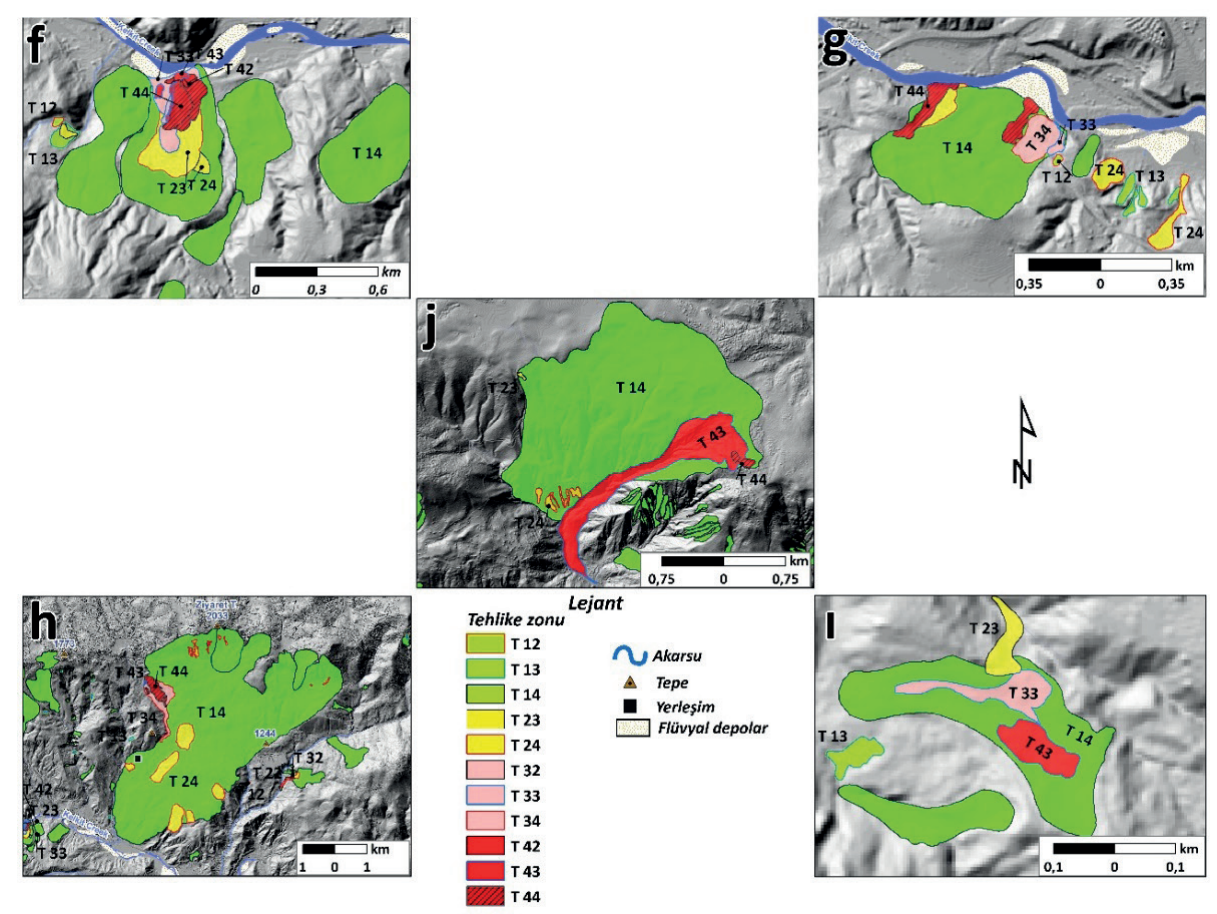

Şekil 4: Heyelan Tehlike Zonları (HTZ).

Figure 4: Landslide Hazard Zones (LHZ). 
heyelan topoğrafyasındaki heyelanlarda ise, 2005 yılında gerçekleşen moloz akması ve bu moloz akmasının ana şevinin gerisine doğru gelişen kısımları çok yüksek "T 43 ve T 44" tehlike zonlarını oluşturmaktadır. Sugözü paleo-heyelan topoğrafyasının güneyinde kaya düşmelerinin de olduğu alanlarda orta seviyede "T 24" tehlike görülürken, bu paleo-heyelanın kuzeydoğusundaki kesimde kayma alanlarında ise orta seviyede tehlike "T 23" görülmektedir. Bunların dışındaki alanlar ise düşük tehlike " $T$ 14" alanlarını oluşturmaktadır (Şekil 4 (j)).

Genel olarak jeomorfolojik tehlike analizine baktığımızda, akarsu topuk erozyonun etkin olduğu Boyalı ve Gökdere heyelanlarının çok yüksek tehlike düzeyine sahip oldukları tespit edilmiştir. Bu heyelanların ilerleyen karakterde olması ve Kelkit Çayının bitişiğinde gelişmesiyle bu iki heyelan bölgesi malzemesini Kelkit Çayına taşımasına neden olmaktadır. Her ne kadar bu alan içinde risk elemanı görülmese de bu bölgede oluşabilecek büyük bir heyelan Kelkit Çayını doldurarak baraj etkisi ile taşkına neden olabilir. Koyulhisar paleo-heyelanının kuzey doğusundaki çok yüksek tehlikedeki Aklan heyelanının bulunduğu kısımda gelişen heyelanların aktivite dağılımının gerileyen ve genişleyen karakterde olması çevresindeki unsurlara tehlike oluşturmaktadır. Ayrıca bu paleo-heyelanın merkezinde bulunan orta tehlikedeki kaymalar, üzerinde bulunan yapılara tehlike oluşturmaktadır. Tehlikenin çok yüksek olduğu bir diğer bölge Sugözü paleo-heyelanın kuzeydoğu kesiminde heyelan aktivitesi yüksek, aktivite dağılımı ise gerileyen karakterde olduğu tespit edilmiştir. Bu heyelanın etki mesafesi; gerileyen karakterde olmasından dolayı gelişimi ana şevin gerisine doğru, moloz akması olarak geliştiğinden dolayı ise etki mesafesi Kelkit Çayı yönü doğru ilerleyen karakterdedir (Şekil 4).

\subsection{Zarar görebilirlik değerlendirmesi}

Tehlikenin tipi ve boyutuna göre risk elamanlarının etkilenebilme derecesini ifade eden zarar görebilirlik (Glade vd., 2006; Van Westen, 2017; Van Westen vd., 2006) sosyal, fiziksel, ekonomik ve sistemik açılardan değerlendirilmektedir. Sosyal zarar görebilirlik olayın yoğunluğuna göre insanlarda oluşabilecek ölüm, sakatlık, zihinsel ve ruhsal bozuklukları içermektedir. Fiziksel zarar görebilirlik olayın yoğunluğuna göre fiziki yapı, altyapı ve diğer unsurların yıkım, hasar olarak etkilenme derecesidir (Douglas, 2007; Glade vd., 2006; Kappes vd., 2012; Papathoma vd., 2011). Ekonomik olarak ise olay bölgesinde yaşayan insanların geçim sağladıkları unsurların tehlikenin yoğunluğundan etkilenme ölçüsüdür (Adrianto \& Matsuda, 2002; Alcántara-Ayala, 2002; Galli \& Guzzetti, 2007; Raddatz, 2009). Bazen ekonomik zarar görebilirlik olayın yaşandığı bölge sınırları dışındaki alanları da etkileyebilmektedir. Örneğin ülke ekonomisine katkı sağlayan bir üretim alanlarının zarar görmesi sonucunda ülke ekonomisi de etkilenebilir. Sistemik zarar görebilirlik ise olay esnasında afet boyutunu azaltacak tahliye yolları, ulaşım ağı, yangın söndürme sistemleri, sağlık tesisleri, güvenlik sistemleri ve enerji tesisleri vb. unsurların heyelan esnasında aksaklığa veya tamamen işlevini kaybedebilme ölçüsünün değerlendirmesidir (Hellström, 2007; Menoni vd., 2002; Pascale vd., 2010). Sistemik zarar görebilirlik olayın tipi ve boyutuna göre değiştiği gibi olayın gerçekleştiği zamanın farklılığına (gece-gündüz, yaz-kış) bağlı olarak ta değişmektedir.

Bölgede yapılan anket, arazi çalışması, arazi kullanımı, gözlem ve uydu görüntülerine bağlı olarak çalışma alanının fiziksel, sosyal, ekonomik ve sistemik zarar görebilirliği değerlendirilmiştir. Zarar görebilirlik değerlendirmesinde heyelan yoğunluğu ve tipine bağlı risk elemanlarının zarar görebilme potansiyeline ilişkin değerlendirmeler yapılmıştır.

Fiziksel zarar görebilirlik için yapı ve altyapı, sosyal zarar görebilirlik için; nüfus, ekonomik zarar görebilirlik için; tarım, sistemik zarar görebilirlik için ise; kritik yapı ve alt yapı gibi risk elemanları değerlendirilmiştir (Tablo 4). Ayrıca gece ve gündüz

Tablo 4: Risk elemanları.

Table 4: Risk elements.

\begin{tabular}{|c|c|c|}
\hline Tipi & Kod & Açıklama \\
\hline \multirow{2}{*}{$\stackrel{\bar{a}}{\frac{\pi}{\pi}}$} & $\underline{\text { YYB }}$ & Yüksek Yoğunluklu Bina \\
\hline & DYB & Düşük Yoğunluklu Bina \\
\hline \multirow{3}{*}{$\frac{\overline{2}}{\frac{2}{\pi}}$} & $\underline{\mathrm{AO}}$ & Anayol-Otoyol \\
\hline & $\underline{\mathrm{in}}$ & İkincil Yol \\
\hline & TKTY & Tali Ve Küçük Taşlı Yol \\
\hline \multirow{11}{*}{ 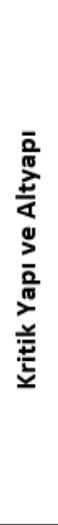 } & $\underline{\text { DT }}$ & Dini Tesis \\
\hline & $\underline{\mathrm{SF}}$ & Spor Faaliyetleri \\
\hline & $\underline{\mathrm{O}}$ & Okul \\
\hline & $\underline{\mathrm{YO}}$ & Yatılı Okul \\
\hline & $\underline{\mathrm{GG}}$ & Güvenlik Güçleri \\
\hline & $\underline{\mathrm{ST}}$ & Sağlık Tesisi \\
\hline & $\underline{\mathrm{YM}}$ & Yönetim Merkezi \\
\hline & $\underline{T}$ & Terminal \\
\hline & $\underline{\text { EK }}$ & Elektrik Kaynağı \\
\hline & $\underline{\mathrm{C}}$ & Cezaevi \\
\hline & $\underline{\mathrm{D}}$ & Diğer \\
\hline \multirow{4}{*}{ 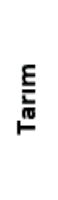 } & $\underline{\text { STA }}$ & Sulu Tarım Alanı \\
\hline & $\underline{\mathrm{KTA}}$ & Kuru Tarım Alanı \\
\hline & $\underline{\text { STNA }}$ & Sulu Tarım Nadaslı Alan \\
\hline & $\underline{\text { KTNA }}$ & Kuru Tarım Nadaslı Alan \\
\hline
\end{tabular}


senaryosuna göre zarar görebilirlik değerlendirmeleri de oluşturulmuştur (Şekil 5). Gece senaryosu sistemik zarar görebilirlik ölçüsünün zamansal değişime bağlı olarak kırsal kesimde bölgenin karanlığın etkisiyle oluşabilecek sistemsel aksamalara bağlı olarak oluşturtulmuştur.

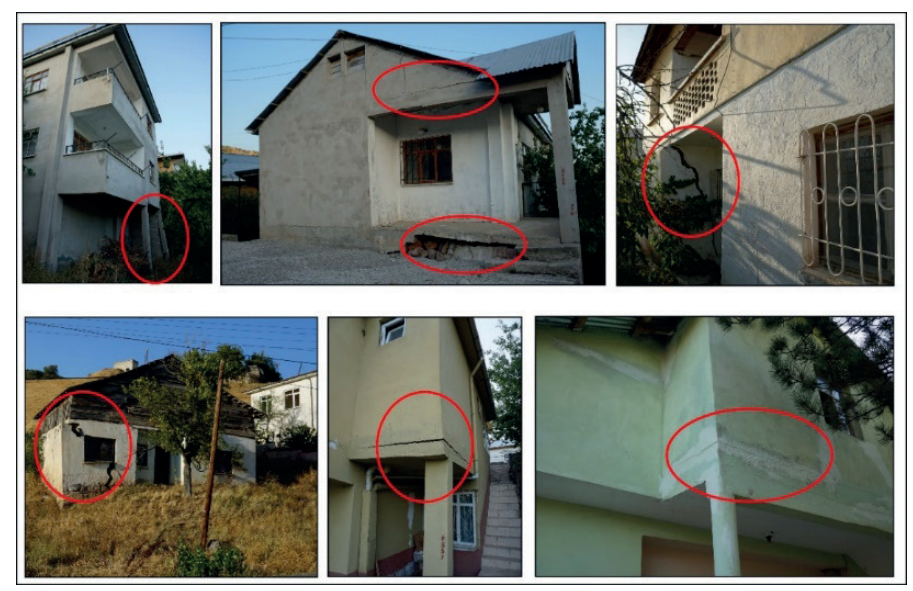

Şekil 5: Çalışma alanında tespit edilen yapısal hasar.

Figure 5: Structural damage was detected in the study area.

Fiziksel ve sosyal zarar görebilirlik için çalışma alanında heyelan tehlikesinin yoğun olduğu alanlarda yapıların ve bu yapılarda yaşayan nüfus ve nüfusun cinsiyet ve yaş durumuna ilişkin anketler düzenlenmiştir (Tablo 6). Bu anketler aynı zamanda heyelan tehlike yoğunluğuna bağlı olarak yapıların hasar görebilirliğini de içermektedir (Şekil 5 ve Şekil 6).

Hasar görebilirlik tespiti için yapılan değerlendirmede " $\mathrm{T}$ 24" seviyesindeki tehlike alanları ikamet edebilme sınırını oluşturmaktadır. Nüfusun bir kısmının bu tehlike alanlarında oturduğu da tespit edilmiştir (Şekil 5 ve Şekil 6).

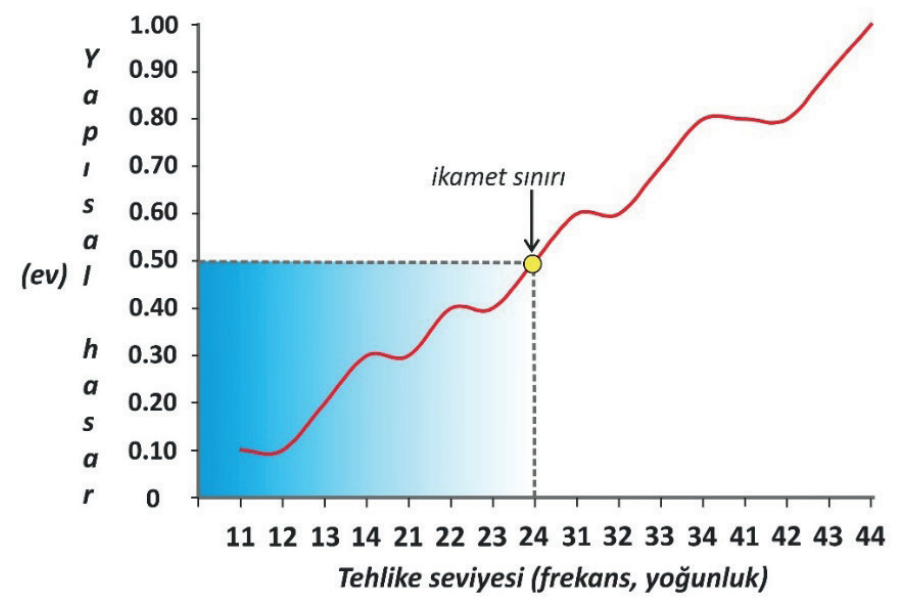

Şekil 6: Yapısal hasar ve tehlike seviyesine göre ikamet edebilme sınırı. Figure 6: Residence limit based on structural damage and hazard levels.

Tablo 5: Gece (A) ve gündüz (B) senaryosuna göre fiziksel, sosyal, sistemik ve ekonomik zarar görebilirlik matrisi.

Table 5: Physical, social, systemic and economic vulnerability matrix according to night (A) and day (B) scenario.

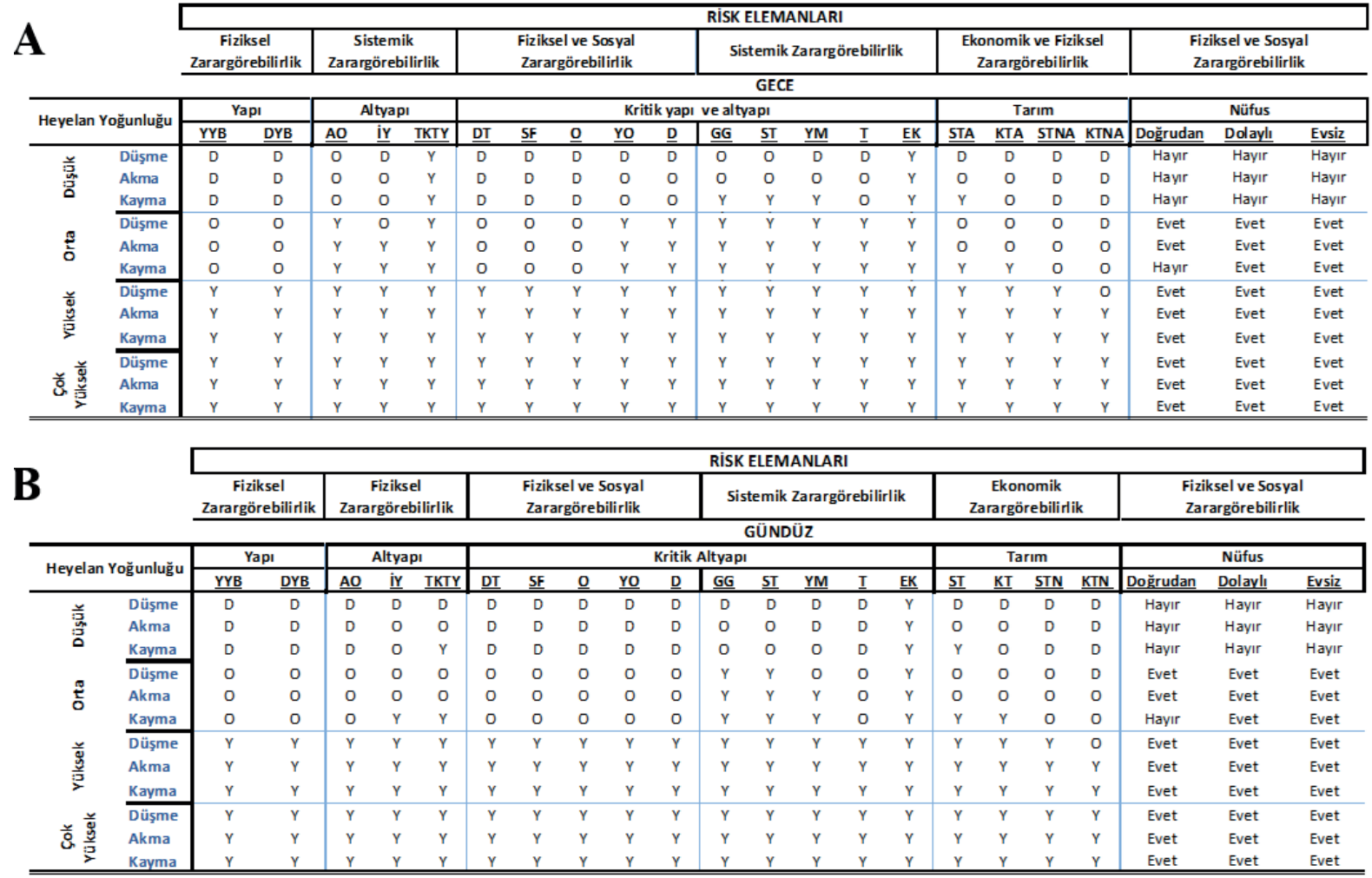


Tablo 6: Tehlike yoğunluğuna göre oturulabilme sınırında bulunan risk elemanlarının özellikleri. Table 6: The characteristics of the risk elements in the residence limit according to the hazard intensity.

\begin{tabular}{|c|c|c|c|c|c|}
\hline Nokta & Kat sayısı & Bina Türü & Hane Sayısı & Cinsiyet & Yaş \\
\hline 1 & 1 & BETONARME & 1 & $\mathrm{E}$ & 75 \\
\hline 2 & 2 & BETONARME & 4 & E-E-K-K & $56-60-18-20$ \\
\hline 3 & 2 & BETONARME & 2 & $E-K$ & $65-67$ \\
\hline 4 & 2 & BETONARME & 7 & E-K-K-K-E & $69-72-41-38-17 * 15 * 11$ \\
\hline 5 & 2 & BETONARME & BOŞ & & \\
\hline 6 & 2 & BETONARME & 4 & E-K-E-K & $37-35-8-11$ \\
\hline 7 & 1 & BETONARME & 1 & $\mathrm{E}$ & 75 \\
\hline 8 & 2 & BETONARME & BOŞ & & \\
\hline 9 & 3 & BETONARME & 1.KAT 1 & K & $70^{*}$ \\
\hline 10 & 3 & BETONARME & 2.KAT 4 & E-E-K-K & $47-57-40-50$ \\
\hline 11 & 3 & BETONARME & 3.KAT 1 & K & 72 \\
\hline 12 & 2 & BETONARME & 1 & K & 80 \\
\hline 13 & 2 & BETONARNE & - & & \\
\hline 14 & 2 & BETONARME & 5 & E-K-K-K-K & $52-42-12-7-4$ \\
\hline 15 & 2 & BETONARME & 1 & K & 70 \\
\hline 16 & 2 & BETONARME & - & & \\
\hline 17 & 2 & BETONARME & - & & \\
\hline 18 & 1 & BETONARME & - & & \\
\hline 19 & 2 & BETONARME & - & & \\
\hline 20 & 2 & BETONARME & - & & \\
\hline 21 & 2 & BETONARME & - & & \\
\hline 22 & 1 & BETONARME & - & & \\
\hline 23 & 1 & TAHTA YAPI GARAJ & 1 Traktör & & 25 BÜYÜKBAŞ VAR \\
\hline 24 & 1 & BETONARME AHIR & 13 Büyükbaş & & \\
\hline 25 & 1 & BETONARMEAHIR & 12 Büyükbaş & & \\
\hline 26 & 1 & BETORNARME ODUNLUK & BOŞ & & \\
\hline 27 & 2 & BETONARME & 2 & $E-K$ & $65-62$ \\
\hline
\end{tabular}

\subsection{Risk Değerlendirmesi}

Risk seviyesi tehlike ve zarar görebilirliğin kesişimini ifade etmektedir. Risk değerlendirmesi " 11 " ile " 44 " arasında değişen 16 koddan tehlike zonu sınıfı ve düşük orta ve yüksek olmak üzere 3 zarar görebilirlik sınıfından oluşmaktadır (Tablo 7).

Tablo 7: Genel olarak risk değerlendirmesine göre risk seviyeleri.

Table 7: Risk levels in general according to risk assessment.

\begin{tabular}{|c|cccc|}
\hline Tehlike & & Düşük & Orta & Toplam \\
\hline \multirow{4}{*}{ Düşük } & 11 & D 11 & O 11 & Y 11 \\
& 12 & D 12 & O 12 & Y 12 \\
& 13 & D 13 & O 13 & Y 13 \\
& 21 & D 21 & O 21 & Y 21 \\
& 14 & D 14 & O 14 & Y 14 \\
& 22 & D 22 & O 22 & Y 22 \\
& 23 & D 23 & O 23 & Y 23 \\
& 31 & D 31 & O 31 & Y 31 \\
& 32 & D 32 & O 32 & Y 32 \\
& 24 & D 24 & O 24 & Y 24 \\
$\downarrow$ & 33 & D 33 & O 33 & Y 33 \\
& 41 & D 41 & O 41 & Y 41 \\
Yüksek & 42 & D 42 & O 42 & Y 42 \\
& 34 & D 34 & O 34 & Y 34 \\
& 43 & D 43 & O 43 & Y 43 \\
& 44 & D 44 & O 44 & Y 44 \\
\hline
\end{tabular}

Tehlike sınıfında kod "11" en düşük, kod "44" en yüksek tehlike alanını tanımlamaktadır. Burada örneğin risk değeri "Y 44" ile tanımlanan bir risk elemanında; Y=yüksek, 44 (ilk sayı tehlike zonunun heyelan sıklığı, ikinci sayı heyelan yoğunluğu) ise tehlike değerini ifade etmektedir.

Fiziksek ve sosyal zarar görebilirliğe göre yapı ve nüfusun risk değerlendirmesinde: Koyulhisar ve Sugözü alanlarında nüfus ve yerleşme bulunduğundan, bu alanlar risklidir. Koyulhisar bölgesinde, Yüksek Yoğunluklu Binalar (YYB) ve Düşük yoğunluklu Binalarda (DYB) "Y 24" ile "Y 14" risk seviyeleri tespit edilmiştir (Şekil 7 (k ve l)). İkamet edebilme sınırını oluşturan "Y 24" risk seviyesi Koyulhisar ilçe merkezini oluşturan Paleo-heyelanının güneyinde DYB'lerde görülmektedir (Şekil 7 (k)).

Sistemik ve sosyal zarar görebilirliğe göre risk değerlendirmesinde ise, sistemik açıdan heyelan gerçekleştiği esnada afeti azalmaya yönelik çalışma yapabilecek Güvenlik (GG) Güçleri ve Yönetim Merkezleri (YM) gibi önemli merkezler ile sosyal açıdan tehlikeye maruz kalma etkisi daha fazla olan Okul alanları ise $(\mathrm{O})$ orta seviyede risk oluşturmaktadır (Şekil 8). 

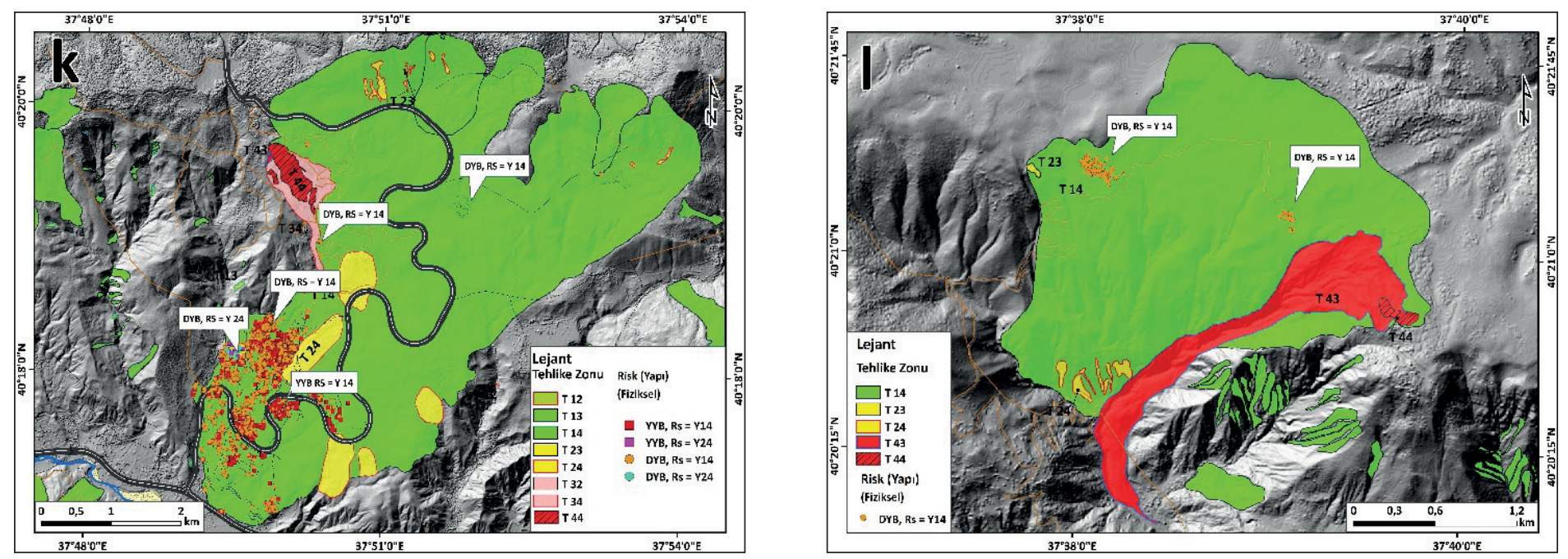

Şekil 7: Koyulhisar (k) ve Sugözünün (I) gündüz senaryosuna göre fiziksel zarar görebilirlik bakımından risk değerlendirmesi.

Figure 7: Risk assessment in terms of physical vulnerability according to the daytime scenario of Koyulhisar (k) and Sugozu (I)

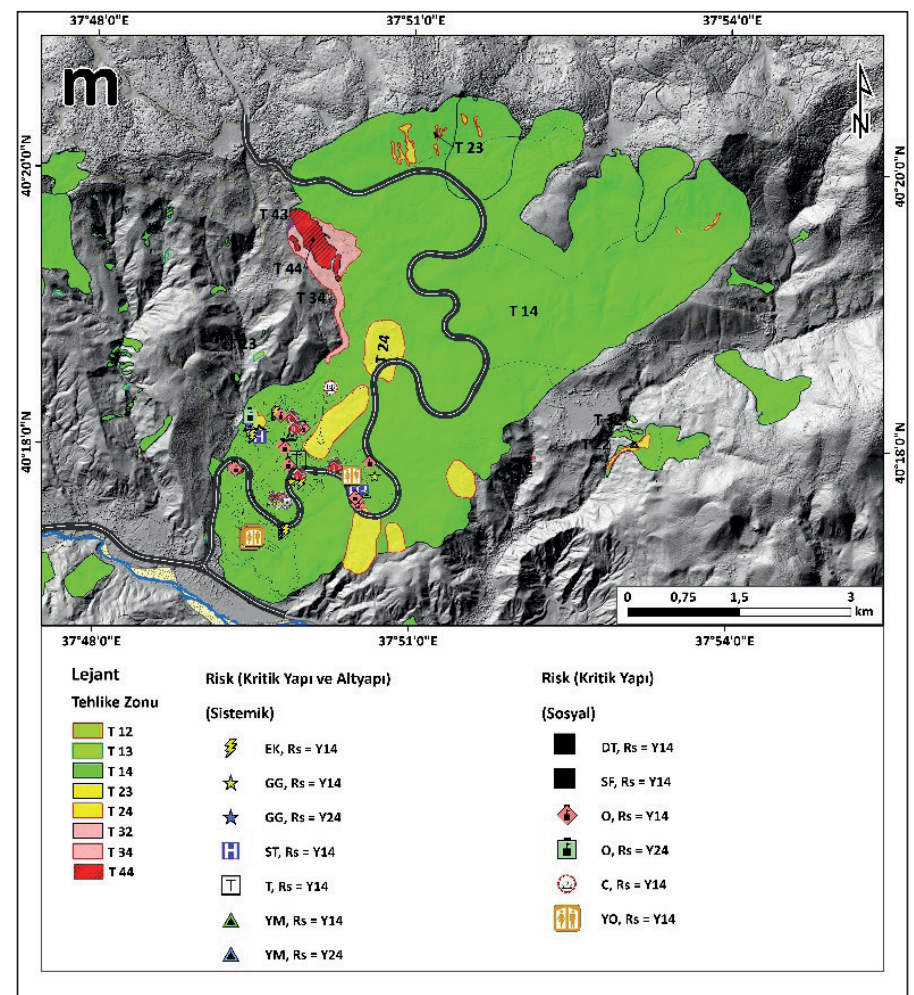

Şekil 8: Koyulhisarın $(m)$ gündüz senaryosuna göre sistemik ve sosyal zarar görebilirlik bakımından risk değerlendirmesi.

Figure 8: Risk assessment of Koyulhisar in terms of systemic and social vulnerability according to (m) daytime scenario.

Fiziksek zarar görebilirliğe göre altyapının risk değerlendirmesinde ele alınan yol tipi risk durumu, Boyalı bölgesinde bulunan ikincil asfalt yol yüksek ve çok yüksek risk seviyesi (Y 33 ve Y 43) (Şekil 9 (n)) tespit edilmiştir. Gökdere de ise düşük risk seviyesinde: Tali Küçük Taşlı Yol (TKTY) bulunmaktadır (Şekil 9 (o)). Koyulhisar bölgesinde düşük seviyede Ana Yollar (AO) (Y 14), düşük ve orta risk seviyede (Y
14 ve Y 24) İkincil Yollar (İY), düşük (Y 14) ve yüksek risk seviyesinde (Y 34) Tali Küçük Taşlı Yollar (TKTY) bulunmaktadır. Sugözü bölgesinde ise, düşük risk seviyesinde (Y 14) Tali Küçük Taşlı Yol (TKTY) görülmektedir. Yollar aynı zamanda sistemik açıdan gece senaryosuna göre de değerlendirilmiştir. Sistemik zarar görebilirliğe göre risk değerlendirmesi fiziksel zarar görebilirlikle aynı sonuçları göstermektedir (Şekil 10). 

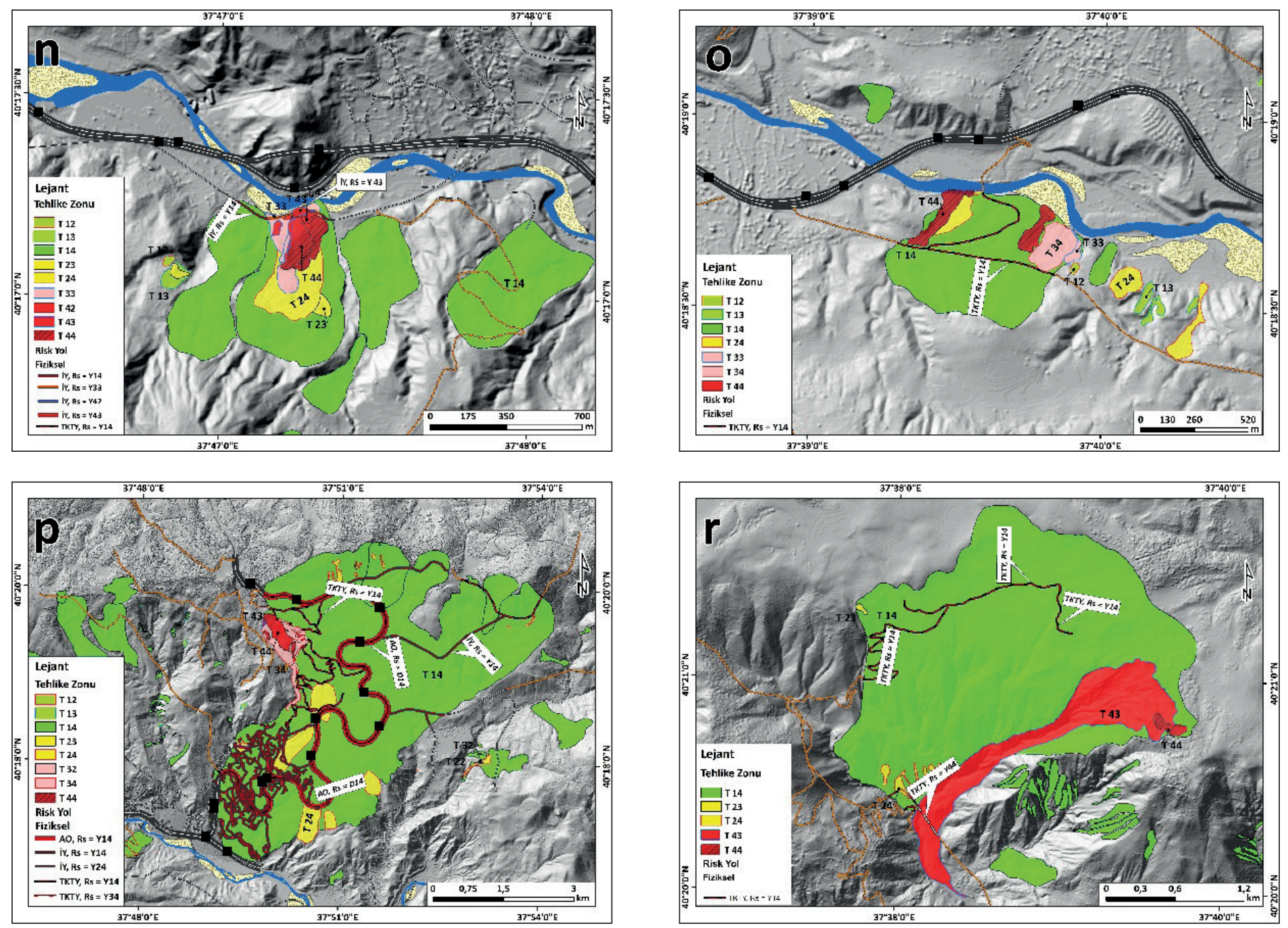

Şekil 9: Boyalı (n), Gökdere (o), Koyulhisar (p) ve Sugözü (r) gündüz senaryosuna göre fiziksel zarar görebilirlilik bakımından altyapı risk değerlendirmesi.

Figure 9: Infrastructure risk assessment in terms of physical vulnerability according to Boyali (n), Gokdere (o), Koyulhisar (p) and Sugozu (r) daytime scenarios.

Ekonomik zarar görebilirliğe tarım alanlarının risk değerlendirmesinde; Koyulhisar ve Gökdere bölgelerinde tarım alanları bulunmaktadır. Koyulhisarda düşük seviyede (Y14) Sulu Tarım Alanı (STA), Kuru Tarım Alanı (KTA), Kuru Tarım Nadaslı Alan (KTNA) ile orta seviyede risk (Y 24) alanı olan Kuru Tarım Nadaslı Alanlar (KTNA), görülmektedir (Şekil 11).

\subsection{Risk Sonuçlarına Göre Maliyet}

$\mathrm{Bu}$ bölümde uzman görüşüne dayalı jeomorfolojik yöntem nitel bir yöntem olmasına rağmen, bu yöntemde fiziksel ve ekonomik zarar görebilirliğe göre belirlenen risk elamanlarının risk seviyelerine göre maliyeti hesaplanabilir. Bu amaçla yol, tarım ve binaları risk seviyesine göre maliyetleri hesaplanmıştır. Burada yol maliyetinin hesaplamasında asfalt yapım fiyat, yol uzunluğu ve genişliğine bağlı olarak yapılmıştır. Anayollar (AO) için hesaplanan asfalt değerinin yanında bu alanda yol için kullanılan banket ve oto korkuluk gibi unsurların fiyatı da eklenmiştir. Ayrıca bu hesaplamalara işçilik ücreti de dahil edilmiştir (Tablo 8). Yapı unsurları ve tarım alanları için maliyet hesabı ise ortalama emlak indeksi $\left(\mathrm{m}^{2}\right)$ fiyatı üzerinden hesaplanmıştır (Tablo 9 ve Tablo 10).

Yol risk seviyesine göre maliyet hesaplanmasında kullanılan malzeme ve yol genişliğine bağlı olarak en fazla maliyet AO tipi yolda görülmektedir. Bu yollar daha çok kaya düşmelerinin tehdidinde bulunmaktadır. Tarım alanlarında ise KTNA alanlar 

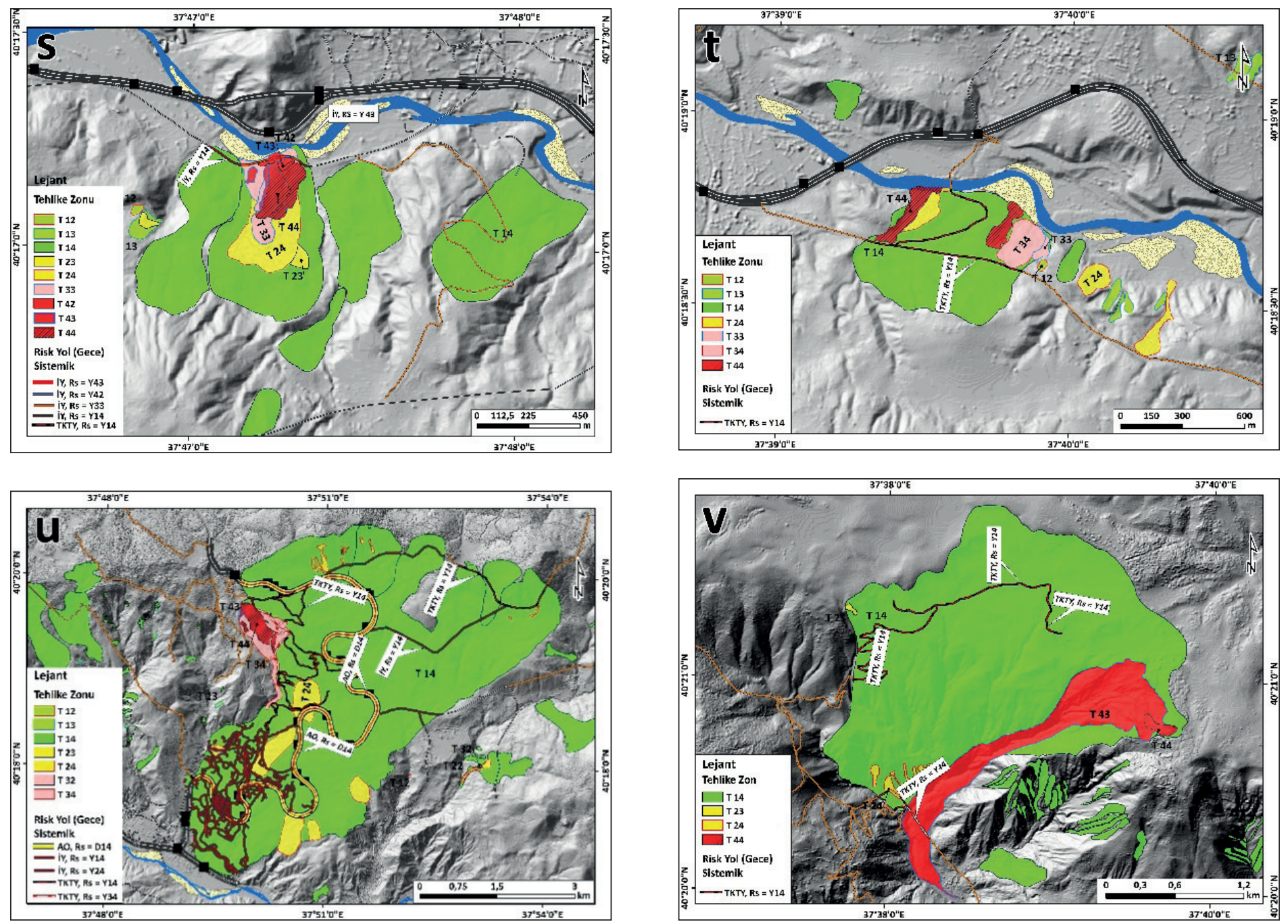

Şekil 10: Boyalı (s), Gökderenin (t), Koyulhisar (u) ve Sugözü (v) gece senaryosuna göre sistemik zarar görebilirlik bakımından altyapı risk değerlendirmesi.

Figure 10: Infrastructure risk assessment in terms of systemic vulnerability according to Boyali (s), Gokderenin ( $t$ ), Koyulhisar (u), and Sugozu (v) night scenarios.
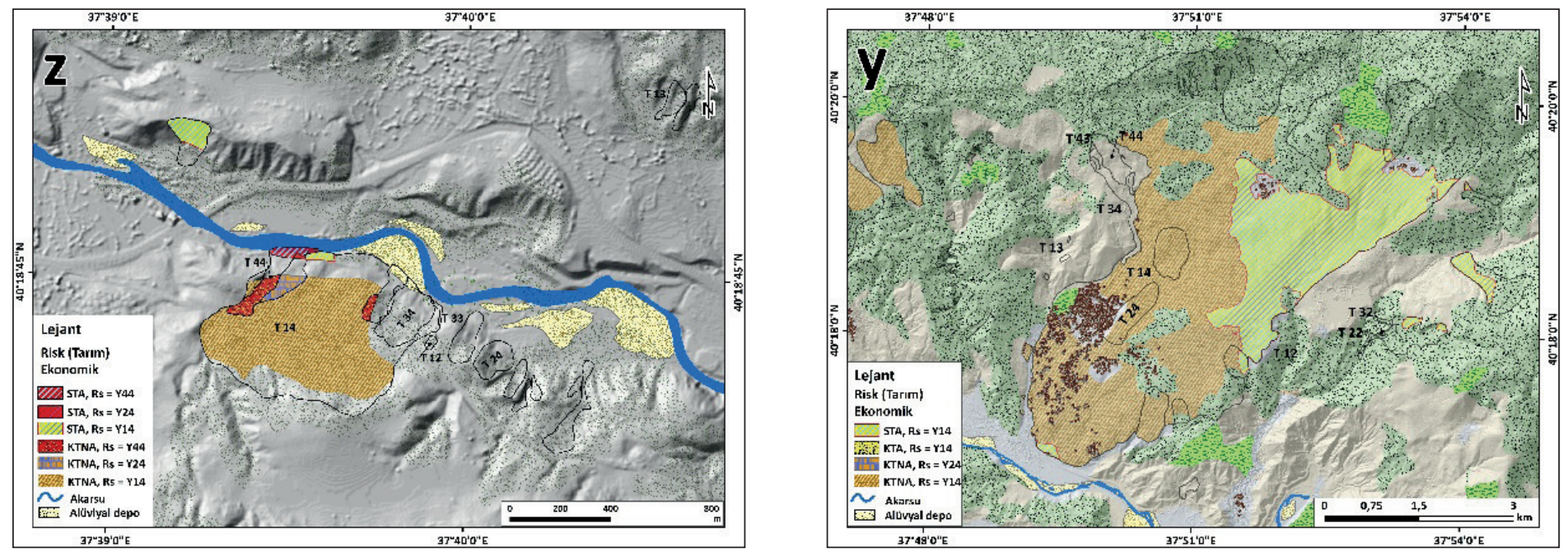

Şekil 11: Gökdere (z) ve Koyulhisarın (y) ekonomik (tarımsal) zarar görebilirliğe göre risk değerlendirmesi.

Figure 11: Risk assessment of Gokdere (z) and Koyulhisar (y) according to economic (agricultural field) vulnerability. 
Tablo 8: Asfalt yol için maliyet belirleme.

Table 8: Cost determination for asphalt road.

\begin{tabular}{lrrr}
\hline Risk seviyesi & Emlak indeksi (TL) & Yapı alanı $\left.\mathbf{( m}^{2}\right)$ & \multicolumn{1}{c}{ Fiyat (TL) } \\
\hline \hline YYB, RS=Y14 & 2.500 & 66.976 & 167.440 .000 \\
YYB, RS=Y24 & 2.500 & 988 & 2.470 .000 \\
DYB, RS=Y14 & 2.500 & 174.414 & 436.035 .000 \\
DYB, RS=Y24 & 2.500 & 3.650 & 9.125 .000
\end{tabular}

Toplam (TL)

246.028

615.070 .000

Tablo 9: Yapı unsurları için maliyet belirleme.

Table 9: Cost determination for structure elements.

\begin{tabular}{lcrr}
\hline \multicolumn{1}{c}{ Risk seviyesi } & Emlak indeks (TL) & Tarım alanı $\left(\mathbf{m}^{\mathbf{2}}\right)$ & Arazi fiyatı $(\mathrm{TL})$ \\
\hline \hline STA, Rs $=$ Y14 & 300 & 5.270 .754 & 1.581 .226 .200 \\
KTA, Rs $=$ Y14 & 300 & 332 & 99.595 \\
KTNA, Rs $=$ Y13 & 300 & 3.443 & 1.032 .756 \\
KTNA, Rs $=$ Y14 & 300 & 10.891 .408 & 3.267 .422 .400 \\
KTNA, Rs = Y24 & 300 & 26.028 & 7.808 .400 \\
KTNA, Rs = Y44 & 300 & 36.965 & 11.089 .500 \\
& & & \\
& Toplam & $\mathbf{1 6 2 2 8 9 2 9 , 5}$ & $\mathbf{1 . 6 2 2 . 8 9 2 . 9 5 0}$ \\
\hline
\end{tabular}

Tablo 10: Tarım alanları için maliyet belirleme.

Table 10: Cost determination for the Agriculture field.

\begin{tabular}{lccc}
\hline \multicolumn{1}{c}{ Risk değeri } & Uzunluk $\left(\mathrm{m}^{2}\right)$ & Toplam maliyet (TL) & Açılama Yol Tipi \\
\hline \hline AO, RS=Y 14 & 200,54 & 2.154 .937 & E80-D100 \\
AO, RS=Y 14 & 28897,5 & 124.004 .085 & D885 \\
iY, RS=Y 13 & 99,36 & 385.683 & \\
iY, RS=Y 14 & 8233653,42 & 31.960 .325 .471 & \\
iY, RS=Y 24 & 636,15 & 2.469 .324 & \\
iY, RS=Y 33 & 146,76 & 569.674 & \\
iY, RS=Y 42 & 38,6 & 149.832 & \\
iY, RS=Y 43 & 74,56 & 289.417 &
\end{tabular}

32.090.348.423

daha fazla risk tehdidi altında bulunup, maliyeti yüksek risk elemanlarını oluşturmaktadır. Yapı unsurlarında ise, DYB binaların daha fazla risk altında olan alanlardır.

\section{TARTIŞMA VE SONUÇ}

Tektonik denetimli Kelkit Çayı'nın oluşturduğu son derece çizgisel ve derin vadi olan çalışma alanı, yükseklik farkları dolayısıyla depremler kadar kütle hareketleri bakımından da son derece aktiftir. Bu alanda Umurca ve Koyulhisar arasında
Türkiye'nin en büyük anakaya heyelanlarından birisi olan Koyulhisar heyelanı $\left(\sim 23.2 \mathrm{~km}^{2}\right), 2005$ yılının bahar döneminde 15 kişinin ölümüyle sonuçlanan Sugözü heyelanı ve plato yamaçlarında iç içe gelişmiş pek çok heyelan bulunmaktadır. Farklı tipte heyelanların tespit edildiği alanda egemen heyelan tipi kayma ve akmalar olarak belirlenmiştir. Heyelan dağılımı açısından vadinin kuzey ve güney yamaçları arasındaki farklılık dikkat çekicidir. Çalışma alanında heyelanların büyük bir kısmının vadinin kuzey kesiminde geliştiği tespit edilmiştir. 
Güney kesimde heyelan yoğunluğunun düştüğü, Kelkit Vadisi yan yamaçlarından ziyade, geride dağlık alanda yer almaktadır ve toplam heyelanlı alan bakımından en yüksek değerlere Bakacak Tepe'nin (1906 m) güney kesiminde rastlanılmaktadır. Vadinin her iki kesiminde ortaya çıkan dağılım ve yoğunluk değerlerinin farklılığının ana nedeni doğrultu atım bileşenli Kuzey Anadolu Fayı'na bağlı olarak ortaya çıkan litolojik kontrast olduğu sonucuna ulaşılmıştır.

Fayın her iki bloğunda farklılık gösteren litolojik birimlerden kuzeyde yüzeylenen Eosen ve Üst Kretase volkanit-çökel kaya birimleri heyelan yoğunluğu değerlerinin en yüksek olduğu birimlerdir. Bölgedeki en önemli yapısal unsur KAF ile faya olan uzaklıktaki noktasal ve alansal heyelan yoğunluğunda heyelan dağılımının faydan bağımsız, buna karşın faydan uzaklığın ilk birkaç kilometresinde alansal olarak daha küçük heyelanların fay tarafından kontrol edildiği tespit edilmiştir. Bu fayın deformasyon zonunun gerisindeki alanda topografik röliyef ve eğim değerlerinin daha yüksek olması ile doğrudan ilişkilidir. Buna karşın bölgede gerçekleşen depremler sonucu tetiklenen heyelanlara ilişkin bir kayıt bulunmaması bunların doğrudan tetikleyici mekanizmayla ilişkilendirilmesini güçleştirmiştir.

Çalışma alanında uzun yıllık yağış ortalamalarına göre en yüksek artışın yıkıcı etkiye sahip büyük heyelanların meydana geldiği 2004-2010 arasındaki periyoda karşl1ık geldiği ortaya konulmuştur. KAF'ın şekillendirdiği vadinin kuzey ve güney arasındaki belirgin bir asimetriden dolayı yağı̧ kuzey kesimde güney kesime oranla daha yüksek ve kısa mesafelerde yükseltiye bağlı olarak değişim göstermektedir. Kuzey bölümde en yüksek yağışlar büyük paleo-heyelanlar içinde gerçekleşen katastrofik heyelanların da bulunduğu havza kuzeyindeki üst kesimlerde ve kireçtaşından oluşan yapısal platonun kenar yamaçlarında meydana gelmektedir.

Topografik bakımdan heyelanların gelişimi ve dağılımı üzerindeki rollerinde genel olarak akmalar üzerinde topografik yükselti ve eğimin rolü yüksektir. Düşmelerde yükselti, eğim ve röliyefin denetleyici bir faktör olarak rolünün kayma ve akmalara göre daha yüksek, kaymalarda ise belirgin bir topografik denetiminin akma ve düşmelere göre olmadığ konulmuştur. Kaymaların diğer heyelan tiplerine göre genel havza topoğrafyasını yansıttı̆̆ görülmüştür. Bunun ana nedeni; ekstrem büyüklükteki kayma tipindeki Koyulhisar heyelanının $\left(\sim 23.2 \mathrm{~km}^{2}\right)$ toplam heyelanlı alanların \%45'ini temsil etmesi ve heyelan gerçekleştikten sonra Koyulhisar yerleşiminin bulunduğu yamaçların eğim oranın düşmesi ve kaymaların topografik değerlerinin de saha ortalamasına benzer bir dağılım göstermesidir (Cihangir, 2018). Mekânsal dağılım açısından topografik faktörlere bakıldığında, yamaç eğim ve topografik röliyef değerlerinin havzanın batısında ve özellikle bu kısımda Kelkit Vadisinin kuzey kesiminde arttığı gözlenmiştir. Buna karş11ık heyelan yoğunluk değerlerindeki artış da dikkat çekicidir. Özellikle kaya düşmelerinin ve yer yer de kayma tipinde büyük ana kaya heyelanlarının yer aldığı bu kesimde akarsu derine kazma oranları da yüksektir (Cihangir, 2018).

Tektonik bakımdan aktif bir alan olan araştırma sahasındaki yükseklik farklarına sebep olan bölgesel yükselime karşılık (Zabcı vd. 2011) akarsuyun yatağını derinleştirmesi havzada belirgin röliyef farklılı̆̆ının temel nedenidir. $\mathrm{Bu}$ farklar ile özellikle Kelkit Vadisi'nin yan yamaçlarında gelişen heyelanların sürekli gençleştiği, bir başka ifadeyle var olan kütlelerin topuklarında meydana gelen akarsu aşındırmasıyla heyelanların tekrardan aktif hale geçerek iç içe birçok heyelanı meydana getirdiği hem geçmiş dönemlere ait hava fotoğraflarında hem de farklı dönemlerde gerçekleştirdiğimiz saha çalışmaları ile gözlenmiştir. Bu alanda meydana gelen Sugözü heyelanı bu sürece verilebilecek iyi örneklerden biridir. Gökçeoğlu vd. (2005) Alanda gelişen birçok heyelanın (ör. Aklan heyelanı (Koyulhisar yerleşiminin kuzeyi)) benzer mekanizmayla tetiklendiği bilinmektedir (Yılmaz, 2009). Özellikle Mart ve Nisan aylarında ani kar erimelerinin gerçekleştiği ve bunların bazı heyelanları tetiklediği saha çalışmaları sırasında yerel idare sorumluları ve yöre halkı ile yapılan görüssmelerde de belirtilmiştir (Cihangir, 2018).

Heyelan aktivitesinin yüksek olduğu çalışma alanında, meydana gelen yamaç yenilenmeleri ve bunların aktivite dağılımı izlenerek 1958-2017 yılları arasında heyelan alanlarında $2,3 \mathrm{~km}^{2}$ 'lik bir artışın meydana geldiği tespit edilmiş̧ir. Büyük ve katastrofik etkiye sahip heyelanların 1990-2006 yılları arasında $\left(1,65 \mathrm{~km}^{2}\right)$ ve daha çok paleo-heyelanlar içerisinde meydana geldiği (örn. Sugözü, Aklan çevresinde) görülmektedir.

Aktivite durumu bakımından; aktif, yeniden aktivite olmuş ve askıda heyelanların bulunduğu, aktivite dağılımı bakımından ise ilerleyen ve genişleyen heyelanların dışında Sugözü ve Koyulhisar bölgelerinde birden fazla aktivite dağılımı görülmektedir. Gerileyen heyelanların kireçtaşı birimlerinde olduğu, genişleyen ve ilerleyen heyelanların ise volkanit-çökel kaya, çakıltaşı-kumtaşı-çamurtaşı birimlerde yaygındır. Aklan ve Su gözü gibi havzanın büyük heyelanları uzun dönemli mekânsal sürekliliğe sahip olduğu tespit edilmiştir. Bu heyelanlar kısa dönemde belirgin olmamalarına karşın meydana geldiği dönemde etki mesafesi ve dolayısıyla oluşturduğu tahribat çok 
yüksektir. Akarsu topuk erozyonun etkisiyle gelişen Kelkit Çayına bitişik Boyalı ve Gökdere heyelanları kısa dönem mekânsal süreklilik üzerinde etkilidir. Aktivite dağılımı ilerleyen karakterdeki bu heyelanların hareketi Kelkit Çayı yönündedir.

Aktivitenin yüksek olduğu dört heyelan bölgesinin farklı kısımlarında tehlikenin şiddeti de değişmektedir. Koyulhisarın kuzeybatısındaki Aklan bölgesi ile güneyindeki ilçe merkezinde tehlike seviyesi daha yüksektir. Burada tehlike seviyesi "T 24" düzeyinde orta düzeydedir. Sugözü bölgesinin kuzeydoğusundaki 2005 moloz akmasindan sonrada heyelan yenilenmeleri bu alanlarda tehlikenin " $\mathrm{T}$ 43" düzeyinde çok yüksek olmasına neden olmuştur. Boyalı alanında orta düzeyden çok yüksek düzeye kadar tehlike alanları bulunmaktadır. Boyalı heyelan bölgesinde heyelan tehlikesi risk elemanlarına tehdit oluşturmaktadır. Burada bulunan tali yollar heyelan malzemeleri ile kapanmaktadır. Ayrıca bu heyelan malzemesi Kelkit Çayına taşımaktadır. İlerki aşamalarda baraj etkisi oluşturma ihtimali yüksektir. Bu dört bölge içerisinde risk elemanları en fazla Koyulhisar bölgesinde yoğunlaşmaktadır. Yapı ve nüfusun büyük çoğunluğu Koyulhisar ilçe merkezinde bulunmaktadır. Bu yapılardan bir kısmı halen aktif olan merkezdeki sığ heyelan üzerinde yer almaktadır. Bu sığ heyelan alanı ikamet edebilme sınırını oluşturmakta olduğundan buradaki yapılar risk altındadır. Bu alanda yapılarda deformasyon, çatlaklar meydana gelmektedir. Bazı binaların tabanın su birikmekte olup, binada çatlaklara neden olmaktadır. Sugözü heyelan alanında ise, yapılar daha çok paleo-heyelanın batı kesiminde bulunmaktadır. $\mathrm{Bu}$ alanda en yüksek tehlike zonunu " $\mathrm{T} 43$ " oluşturan kuzulu heyelan moloz akmasının birikim zonun ön kısmında kısmi bahçe tarımı yapılmaktadır. Bu durum yüksek risk oluşturmaktadır.

Genel olarak bakıldığında yol ağı en fazla Koyulhisar bölgesinde bulunmaktadır. Bu bölgenin önemli bağlantıların kesişim noktasında bulunması ve kritik yapıları birbirine bağlaması bu bölgede fiziksel ve sistemik zarar görebilirliğe göre risk seviyesini yükseltmektedir. Sistemik unsurların Koyulhisar paleo-heyelanında, heyelan frekansının en sık olduğu alanda yer alması dezavantaj oluşturmaktadır. Ayrıca Koyulhisar bölgesinde $\mathrm{m}^{2}$ ye düşen insan sayısının en yoğun olduğu alanlar (okul, dini tesis, sosyal tesis) sosyal zarar görebilirliğe göre riske sahiptir. Heyelan riskinin en yüksek olduğu alanlardan biri olan Boyalı bölgesinde İkincil yollar zaman zaman heyelan malzemesi ile de örtülmektedir. Ekonomik zarar görebilirlik açıdan risk ise, daha çok Koyulhisar bölgesinde görüldüğü tespit edilmiştir.

Risk maliyet durumuna bakıldığında; Jeomorfolojik yaklaşıma göre tüm risk düzeylerinde toplam yol maliyeti
32.090.348.423 TL'dir. Bu maliyet yapı unsurları için toplam maliyet 615.070 .000 TL'dir. Tarım için ise toplam maliyet 1.622.892.950 TL'dir. Bu maliyetler maksimum toplam risk maliyetini ifade etmektedir.

Genel olarak çalışma kapsamında belirlenen risk elemanlarının risk düzeyini ifade eden çıktılar, oluşabilecek bir afetin zararının minimum düzeyde olması için planlama ve önleme aşamasında karar vericilere destek sağlamasının yanında, ayrıca tehlike sonucu oluşabilecek risk maliyeti ile karar vericilere yarar sağlayacaktır. Bu risk haritaları ile DSİ, valilik, imar revizyonu için belediye, gibi resmi ve özel kurum kuruluşları çalışmalarında altlık niteliğinde kullanılabilir. Böylece bu çalışma kapsamında ele alınan bilimsel bakımdan söz konusu risklerin belirlenmesi ile bir doğa olayının afet boyutu ulaşması durumunda beşeri varlıkların bu süreçte minimum düzeyde etkilenmesini hedeflemiş ve bu yönüyle çalışmanın gelecekte pratiğe taşınması ile topluma gereken hizmeti sunmuş olacağı kanaatindeyiz.

Teşekkür: Tolga Görüm'e yol göstericiliğinden ve yardımlarından dolayı teşekkürlerimi sunarım.

Hakem Değerlendirmesi: Dış bağımsız.

Çıkar Çatışması: Yazar çıkar çatışması bildirmemiştir

Finansal Destek: İstanbul Üniversitesi Bilimsel Araştırmalar Projeleri Birimi (BAP) tarafindan 55865 nolu proje ile desteklenmiştir.

Peer-review: Externally peer-reviewed.

Conflict of Interest: The author has no conflict of interest to declare.

Grant Support: This study supported by Istanbul University Scientific Research Projects Unit (BAP) with project number 55865.

\section{KAYNAKÇA/REFERENCES}

Adrianto, L., \& Matsuda, Y. (2002). Developing economic vulnerability indices of environmental disasters in small island regions. Environmental Impact Assessment Review, 22(4), 393-414. https:// doi.org/https://doi.org/10.1016/S0195-9255(02)00012-4

AFAD. (2020). Afet Yönetimi Kapsamında 2019 Yılına Bakış ve Doğa Kaynaklı Olay Istatistikleri Raporu.

Alcántara-Ayala, I. (2002). Geomorphology, natural hazards, vulnerability and prevention of natural disasters in developing countries. Geomorphology, 47(2), 107-124. https://doi.org/https:// doi.org/10.1016/S0169-555X(02)00083-1

Atkinson, P. M., \& Massari, R. (1998). Generalised linear modelling of susceptibility to landsliding in the central Apennines, Italy. Computers \& Geosciences, 24(4), 373-385. https://doi.org/https:// doi.org/10.1016/S0098-3004(97)00117-9 
Ayenew, T., \& Barbieri, G. (2005). Inventory of landslides and susceptibility mapping in the Dessie area, northern Ethiopia. Engineering Geology, 77(1-2), 1-15. https://doi.org/https://doi. org/10.1016/j.enggeo.2004.07.002

Brabb, E. E., \& Pampeyan, E. H. (1972). Preliminary map of landslide deposits in San Mateo County, California.

Cannon, S. H., \& Ellen, S. (1985). Rainfall conditions for abundant debris avalanches, San Francisco Bay region, California. California geology, 38(12), 267-272.

Cardinali, M., Galli, M., Ardizzone, F., Guzzetti, F., \& Reichenbach, P. (2007). Comparing landslide rates in the northern and central Apennines, Italy. Geophysical Research Abstracts,

Cardinali, M., Reichenbach, P., Guzzetti, F., Ardizzone, F., Antonini, G., Galli, M., Cacciano, M., Castellani, M., \& Salvati, P. (2002). A geomorphological approach to the estimation of landslide hazards and risks in Umbria, Central Italy. Natural Hazards and Earth System Science, 2(1/2), 57-72. https://doi.org/https://doi. org/10.5194/nhess-2-57-2002

Carrara, A., Cardinali, M., Detti, R., Guzzetti, F., Pasqui, V., \& Reichenbach, P. (1991). GIS techniques and statistical models in evaluating landslide hazard. Earth Surface Processes and Landforms, 16(5), 427-445. https://doi.org/https://doi.org/10.1002/ esp.3290160505

Chau, K., Sze, Y., Fung, M., Wong, W., Fong, E., \& Chan, L. (2004). Landslide hazard analysis for Hong Kong using landslide inventory and GIS. Computers \& Geosciences, 30(4), 429-443. https://doi. org/https://doi.org/10.1016/j.cageo.2003.08.013

Cihangir, M. E. (2018). Kelkit Çayı Vadisinde (Umurca-Koyulhisar Arast) Heyelan Riskinin Belirlenmesi (Publication Number 522001) [Unpublished $\mathrm{PhD}$ thesis, Istanbul University]. Istanbul.

Cihangir, M. E., \& Gorum, T. (2016). Kelkit Vadisinin Aşağı Çığrında Gelişmiş Heyelanların Dağılım Deseni ve Oluşumlarını Kontrol Eden Faktörler. Türk Cografya Dergisi, 0(66). https://doi.org/ https://doi.org/10.17211/tcd.84731

Cihangir, M. E., \& Görüm, T. (2016). Kelkit vadisinin aşağı çığırında gelişmiş heyelanların dağılım deseni ve oluşumlarını kontrol eden faktörler. Türk Cografya Dergisi, (66), 19-28.

Cihangir, M. E., Görüm, T., \& Nefeslioğlu, H. A. (2018). Heyelan tetikleyici faktörlerine bağlı mekânsal hassasiyet değerlendirmesi. Türk Cografya Dergisi, (70), 133-142. https://doi.org/https://doi. org/10.17211/tcd.410998

Cotecchia, F., Lollino, P., Santaloia, F., Vitone, C., \& Mitaritonna, G. (2009). A research project for deterministic landslide risk assessment in Southern Italy: methodological approach and preliminary results. Geotechnical risk and safety. Taylor \& Francis Group, London, 363-370.

Crozier, M. J., \& Glade, T. (2005). Landslide hazard and risk: issues, concepts and approach. Landslide hazard and risk, 1-40.

Cruden, D., \& Varnes, D. (1996). Landslide types and processes., In, Landslides: investigation and mitigation., Edited by, A. K. Turner and R. L. Schuster. Transportation Research Board, Special Report 247, pp. 36-75.
Cruden, D., \& Varnes, D. (1996). Landslides: investigation and mitigation. Chapter 3-Landslide types and processes. Transportation research board special report (247).

Cruden, D. M., \& Fell, R. (1997). Landslide risk assessment. AA Balkema Rotterdam.

Cutter, S. L., Boruff, B. J., \& Shirley, W. L. (2003). Social vulnerability to environmental hazards. Social science quarterly, 84(2), 242-261. https://doi.org/https://doi.org/10.1111/1540-6237.8402002

Dai, F., \& Lee, C. (2002). Landslide characteristics and slope instability modeling using GIS, Lantau Island, Hong Kong. Geomorphology, 42(3), 213-228. https://doi.org/https://doi.org/10.1016/S0169$555 \mathrm{X}(01) 00087-3$

Dai, F., Lee, C., \& Ngai, Y. Y. (2002). Landslide risk assessment and management: an overview. Engineering Geology, 64(1), 65-87. https://doi.org/https://doi.org/10.1016/S0013-7952(01)00093-X

Demir, G. (2018). Coğrafi Bilgi Sistemleri ile Suşehri (Sivas) Heyelan Duyarlılık Analizi. Gümüşhane Üniversitesi Fen Bilimleri Enstitüsü Dergisi, 8(1), 96-112.

Demirel, M., Tatar, O., \& Koçbulut, F. (2016). Kuzey Anadolu Fay Zonu Üzerinde Koyulhisar (Sivas) ve Yakın Çevresindeki Fayların Kinematik Özellikleri. Türkiye Jeoloji Bülteni, 59(3), 357-370.

Douglas, J. (2007). Physical vulnerability modelling in natural hazard risk assessment. Natural Hazards and Earth System Science, 7(2), 283-288. https://doi.org/https://doi.org/10.5194/nhess-7-283-2007

Duman, T. Y., Can, T., Gokceoglu, C., Nefeslioglu, H. A., \& Sonmez, H. (2006). Application of logistic regression for landslide susceptibility zoning of Cekmece Area, Istanbul, Turkey. Environmental Geology, 51(2), 241-256. https://doi.org/10.1007/s00254-006-0322-1

Dwyer, A., Zoppou, C., Nielsen, O., Day, S., \& Roberts, S. (2004). Quantifying social vulnerability: a methodology for identifying those at risk to natural hazards. Geoscience Australia Canberra.

Ercanoglu, M., \& Gokceoglu, C. (2002). Assessment of landslide susceptibility for a landslide-prone area (north of Yenice, NW Turkey) by fuzzy approach. Environmental Geology, 41(6). https:// doi.org/DOI 10.1007/s00254-001-0454-2

Ercanoglu, M., \& Gokceoglu, C. (2004). Use of fuzzy relations to produce landslide susceptibility map of a landslide prone area (West Black Sea Region, Turkey). Engineering Geology, 75(3-4), 229 250. https://doi.org/https://doi.org/10.1016/j.enggeo.2004.06.001

Erdem, F. (1987). Kelkit Havzasında Sediment Erozyon İlişkileri. Jeomorfoloji Dergisi, 15, 65-73, Ankara.

Galli, M., \& Guzzetti, F. (2007). Landslide vulnerability criteria: a case study from Umbria, Central Italy. Environmental management 40(4), 649-665.

Glade, T., Anderson, M. G., \& Crozier, M. J. (2006). Landslide hazard and risk. John Wiley \& Sons.

Gokceoglu, C., Sonmez, H., Nefeslioglu, H. A., Duman, T. Y., \& Can, T. (2005). The 17 March 2005 Kuzulu landslide (Sivas, Turkey) and landslide-susceptibility map of its near vicinity. Engineering Geology, 81(1), 65-83. 
Gökceoglu, C., \& Aksoy, H. (1996). Landslide susceptibility mapping of the slopes in the residual soils of the Mengen region (Turkey) by deterministic stability analyses and image processing techniques. Engineering Geology, 44(1-4), 147-161. https://doi.org/https://doi. org/10.1016/S0013-7952(97)81260-4

Guzzetti, F. (2006). Landslide hazard and risk assessment Universitätsund Landesbibliothek Bonn].

Guzzetti, F., Ardizzone, F., Cardinali, M., Rossi, M., \& Valigi, D. (2009). Landslide volumes and landslide mobilization rates in Umbria, central Italy. Earth and Planetary Science Letters, 279(3), 222-229. https://doi.org/https://doi.org/10.1016/j.epsl.2009.01.005

Guzzetti, F., Carrara, A., Cardinali, M., \& Reichenbach, P. (1999). Landslide hazard evaluation: a review of current techniques and their application in a multi-scale study, Central Italy. Geomorphology, 31(1), 181-216. https://doi.org/https://doi.org/10.1016/S0169-555X(99)00078-1

Guzzetti, F., Reichenbach, P., Cardinali, M., Galli, M., \& Ardizzone, F. (2005). Probabilistic landslide hazard assessment at the basin scale. Geomorphology, 72(1-4), 272-299.

Gürsoy, H., Tatar, O., Koçbulut, F., Mesci, B. L., Akpınar, Z., Tunçer D, \& Yaman, S. (2006). "Kuzulu (Sugözü-KoyulhiSAR, Sivas) heyelan bölgesinin temel jeolojik özellikleri: heyelan sahasinda gözlenen tektonik yapıların heyelanın gelişiminde rolü var mı? ATAG10 Aktif Tektonik Araştırma Grubu 10. Toplantıs1,

Hastaoğlu, K., Poyraz, F., Türk, T., Koçbulut, F., Şanlı, D., Yılmaz, I., Balık Şanlı, F., Kuçak, R., Demirel, M., \& Gürsoy, Ö. (2014). GPS ve Ps-Insar Yöntemleri Kullanılarak Koyulhisar (Sivas) Heyelanlarının İzlenmesi: İlk Sonuçlar. Gümüşhane Üniversitesi Fen Bilimleri Enstitüsü Dergisi, 4(2).

Hellström, T. (2007). Critical infrastructure and systemic vulnerability: Towards a planning framework. Safety science, 45(3), 415-430. https://doi.org/https://doi.org/10.1016/j.ssci.2006.07.007

Howe, E. (1909). Landslides in the San Juan Mountains, Colorado: including a consideration of their causes and their classification. US Government Printing Office.

Iverson, R. M., Schilling, S. P., \& Vallance, J. W. (1998). Objective delineation of lahar-inundation hazard zones. Geological Society of America Bulletin, 110(8), 972-984. https://doi.org/https://doi. org/10.1130/0016-7606(1998)110\%3C0972:ODOLIH\%3E2.3.CO;2

Jones, F. O. (1961). Landslides along the Columbia river valley, Northeastern Washington. US Government Printing Office.

Juang, C., Lee, D., \& Sheu, C. (1992). Mapping slope failure potential using fuzzy sets. Journal of geotechnical engineering, 118(3), 475-494.

Kanungo, D., Arora, M., Sarkar, S., \& Gupta, R. (2006). A comparative study of conventional, ANN black box, fuzzy and combined neural and fuzzy weighting procedures for landslide susceptibility zonation in Darjeeling Himalayas. Engineering Geology, 85(3), 347-366. https://doi.org/https://doi.org/10.1016/j.enggeo.2006.03.004

Kappes, M. S., Papathoma-Koehle, M., \& Keiler, M. (2012). Assessing physical vulnerability for multi-hazards using an indicator-based methodology. Applied Geography, 32(2), 577-590. https://doi.org/ https://doi.org/10.1016/j.apgeog.2011.07.002
Keçer, M. v. T., K. (1986). Kuzey Anadolu Fayına Bağlı Olarak Neotektonik Dönemde Oluşan Suşehri Havzası'nın Evrimi. Jeomorfoloji Dergisi, 14, 57-63, Ankara.

Malamud, B. D., Turcotte, D. L., Guzzetti, F., \& Reichenbach, P. (2004). Landslide inventories and their statistical properties. Earth Surface Processes and Landforms, 29(6), 687-711. https://doi.org/https:// doi.org/10.1002/esp.1064

Menoni, S., Molinari, D., Parker, D., Ballio, F., \& Tapsell, S. (2012). Assessing multifaceted vulnerability and resilience in order to design risk-mitigation strategies. Natural hazards, 64(3), 2057-2082.

Menoni, S., Pergalani, F., Boni, M., \& Petrini, V. (2002). Lifelines earthquake vulnerability assessment: a systemic approach. Soil Dynamics and Earthquake Engineering, 22(9), 1199-1208. https:// doi.org/https://doi.org/10.1016/S0267-7261(02)00148-3

MTA. (2005). Kuzulu (Sivas-Koyulhisar) Heyelanı.

Nandi, A., \& Shakoor, A. (2010). A GIS-based landslide susceptibility evaluation using bivariate and multivariate statistical analyses. Engineering Geology, 110(1), 11-20. https://doi.org/https://doi. org/10.1016/j.enggeo.2009.10.001

Okay, A. I. (2008). Geology of Turkey: a synopsis. Anschnitt, 21, 1942.

Pachauri, A., Gupta, P., \& Chander, R. (1998). Landslide zoning in a part of the Garhwal Himalayas. Environmental Geology, 36(3), 325-334.

Pachauri, A., \& Pant, M. (1992). Landslide hazard mapping based on geological attributes. Engineering Geology, 32(1-2), 81-100. https://doi.org/https://doi.org/10.1016/0013-7952(92)90020-Y

Papathoma, M., Kappes, M., Keiler, M., \& Glade, T. (2011). Physical vulnerability assessment for alpine hazards: state of the art and future needs. Natural hazards, 58(2), 645-680.

Pascale, S., Sdao, F., \& Sole, A. (2010). A model for assessing the systemic vulnerability in landslide prone areas. Natural Hazards and Earth System Sciences, 10(7), 1575-1590. https://doi.org/ https://doi.org/10.5194/nhess-10-1575-2010

Pelling, M. (2003). The vulnerability of cities: natural disasters and social resilience. Earthscan.

Raddatz, C. E. (2009). The wrath of God: macroeconomic costs of natural disasters. World Bank Policy Research Working Paper No. 5039, 30 .

Ruff, M., \& Czurda, K. (2008). Landslide susceptibility analysis with a heuristic approach in the Eastern Alps (Vorarlberg, Austria). Geomorphology, 94(3), 314-324. https://doi.org/https://doi. org/10.1016/j.geomorph.2006.10.032

Seymen, İ. (1975). Kelkit vadisi kesiminde Kuzey Anadolu Fay zonunun tektonik özelliği İTÜ].

Tatar, O., Poyraz, F., Gursoy, H., Cakir, Z., Ergintav, S., Akpınar, Z., Kocbulut, F., Sezen, F., Turk, T., \& Hastaoglu, K. Ö. (2012). Crustal deformation and kinematics of the Eastern Part of the North Anatolian Fault Zone (Turkey) from GPS measurements. Tectonophysics, 518. https://doi.org/https://doi.org/10.1016/j. tecto.2011.11.010 
Toprak, V. (1989). Tectonic and stratigraphic characteristics of the Koyulhisar segment of the North Anatolian Fault Zone (Sivas, Turkey) $\mathrm{PhD}$ thesis, Middle East Technical University, Ankara].

Van Westen. (2017). Multi-hazard risk assessment and decision making. In N. Dalezios (Ed.), Environmental Hazards Methodologies for Risk Assessment and Management (pp. 31-91). IWA Publishing.

Van Westen, Van Asch, \& Soeters, R. (2006). Landslide hazard and risk zonation-why is it still so difficult? Bulletin of Engineering Geology and the Environment, 65(2), 167-184.

Van Westen, C., Van Asch, T. W., \& Soeters, R. (2006). Landslide hazard and risk zonation-why is it still so difficult? Bulletin of Engineering Geology and the Environment, 65(2), 167-184.

Varnes, D. J. (1958). Landslide types and processes. Landslides and engineering practice, 24, 20-47.

Varnes, D. J. (1978). Slope movement types and processes. Special report, $176,11-33$.

Wachal, D. J., \& Hudak, P. F. (2000). Mapping landslide susceptibility in Travis County, Texas, USA. GeoJournal, 51(3), 245-253.

Van Westen, C. v., \& Terlien, M. (1996). An approach towards deterministic landslide hazard analysis in GIS. A case study from Manizales (Colombia). Earth Surface Processes and Landforms, 21(9), 853-868. https://doi.org/https://doi.org/10.1002/(SICI)10969837(199609)21:9\%3C853::AID-ESP676\%3E3.0.CO;2-C
Wieczorek, G. F. (1984). Preparing a detailed landslide-inventory map for hazard evaluation and reduction. Bull Assoc Eng Geol, 21(3), 337-342.

Wieczorek, G. F., Wilson, R. C., \& Harp, E. L. (1985). Map showing slope stability during earthquakes in San Mateo County, California.

Yesilnacar, E., \& Topal, T. (2005). Landslide susceptibility mapping: A comparison of logistic regression and neural networks methods in a medium scale study, Hendek region (Turkey). Engineering Geology, 79(3-4), 251-266. https://doi.org/https://doi.org/10.1016/j. enggeo.2005.02.002

Yıldırım, A. (2006). Koyulhisar-Kuzulu (Sivas) Heyelanının Jeomorfolojik Etüdü. Doğu Coğrafya Dergisi, 11(15).

Yilmaz, A., Oral, A., \& Bilgic, T. (1985). Yukarı Kelkit Çayı yöresi ve güneyinin temel jeoloji özellikleri ve sonuçları (MTA raporu, Issue.

Yilmaz, I. (2009). A case study from Koyulhisar (Sivas-Turkey) for landslide susceptibility mapping by artificial neural networks. Bulletin of Engineering Geology and the Environment, 68(3), 297306. 